\title{
Remote sensing and inverse transport modeling of the Kasatochi eruption sulfur dioxide cloud
}

\author{
N. I. Kristiansen, ${ }^{1}$ A. Stohl, ${ }^{1}$ A. J. Prata, ${ }^{1}$ A. Richter, ${ }^{2}$ S. Eckhardt, ${ }^{1}$ P. Seibert, ${ }^{3}$ \\ A. Hoffmann, ${ }^{4}$ C. Ritter, ${ }^{4}$ L. Bitar, ${ }^{5}$ T. J. Duck, ${ }^{5}$ and K. Stebel ${ }^{1}$ \\ Received 27 September 2009; revised 10 June 2010; accepted 17 June 2010; published 5 November 2010.
}

[1] An analytical inversion method is used to estimate the vertical profile of sulfur dioxide $\left(\mathrm{SO}_{2}\right)$ emissions from the major 2008 eruption of Kasatochi Volcano, located on the Aleutian Arc, Alaska. The method uses satellite-observed total $\mathrm{SO}_{2}$ columns from the Global Ozone Monitoring Experiment-2 (GOME-2), Ozone Monitoring Instrument (OMI), and Atmospheric InfraRed Sounder (AIRS) during the first 2 days after the eruption, and an atmospheric transport model, FLEXPART, to calculate the vertical emission profile. The inversion yields an emission profile with two large emission maxima near $7 \mathrm{~km}$ above sea level (asl) and around $12 \mathrm{~km}$ asl, with smaller emissions up to $20 \mathrm{~km}$. The total mass of $\mathrm{SO}_{2}$ injected into the atmosphere by the eruption is estimated to $1.7 \mathrm{Tg}$, with $\sim 1 \mathrm{Tg}$ reaching the stratosphere (above $10 \mathrm{~km}$ asl). The estimated vertical emission profile is robust against changes of the assumed eruption time, meteorological input data, and satellite data used. Using the vertical emission profile, a simulation of the transport extending for 1 month after the eruption is performed. The simulated cloud agrees very well with $\mathrm{SO}_{2}$ columns observed by GOME-2, OMI, and AIRS until 6 days after the eruption, and the altitudes agree with both Cloud-Aerosol Lidar and Infrared Pathfinder Satellite Observation measurements and ground-based lidar observations to within $1 \mathrm{~km}$. The method is computationally very fast. It is therefore suitable for implementation within an operational environment, such as the Volcanic Ash Advisory Centers, to predict the threat posed by volcanic emissions for air traffic.

Citation: Kristiansen, N. I., et al. (2010), Remote sensing and inverse transport modeling of the Kasatochi eruption sulfur dioxide cloud, J. Geophys. Res., 115, D00L16, doi:10.1029/2009JD013286.

\section{Introduction}

[2] Volcanic eruptions can inject particles and gases high into the atmosphere. Generally, the major component is tephra, also called volcanic ash, which is solidified material. The most abundant gases emitted are water vapor $\left(\mathrm{H}_{2} \mathrm{O}\right)$ and carbon dioxide $\left(\mathrm{CO}_{2}\right)$. Another important gas emitted by volcanic eruptions is sulfur dioxide $\left(\mathrm{SO}_{2}\right)$ which is converted to sulfate aerosols in the atmosphere by reacting with the $\mathrm{OH}$ radical. $\mathrm{SO}_{2}$ injections in to the stratosphere are of great importance since the sulfate particles have a long residence time here and strongly interact with solar radiation by scattering and thus increase Earth's albedo [Textor et al., 2003]. The particles can also cause ozone depletion on a global scale

\footnotetext{
${ }^{1}$ Norwegian Institute for Air Research, Kjeller, Norway.

${ }^{2}$ Institute of Environmental Physics, University of Bremen, Bremen, Germany.

${ }^{3}$ Institute of Meteorology, University of Natural Resources and Applied Life Sciences, Vienna, Austria.

${ }^{4}$ Alfred Wegener Institute, Potsdam, Germany.

${ }^{5}$ Department of Physics and Atmospheric Science, Dalhousie University, Halifax, Nova Scotia, Canada.

Copyright 2010 by the American Geophysical Union. 0148-0227/10/2009JD013286
}

[e.g., Solomon et al., 1998]. Explosive volcanic eruptions can emit $\mathrm{SO}_{2}$ to very high altitudes (greater than $10 \mathrm{~km}$ above sea level [asl]) in contrast to anthropogenic and other emissions which occur mostly at low altitudes. Notice: hereafter all altitudes are in $\mathrm{km}$ asl, unless otherwise specified.

[3] Airborne volcanic ash is a danger to aircraft because it can cause serious damage, and even loss of power on the engines [Casadevall, 1994]. There are nine Volcanic Ash Advisory Centers (VAACs) around the world that advise international aviation of the location and movement of volcanic ash clouds. The VAACs use satellite information, ground reports from volcanological agencies, pilot reports, meteorological knowledge and numerical models to track and forecast ash movement so that aircraft can fly around or over the airborne ash safely [International Civil Aviation Organization (ICAO), 2004]. A fundamental piece of information required by the VAACs is the location and height of the ash clouds, as this is the principal determinant of the ash transport and potential hazard to jet aircraft.

[4] For nonexplosive volcanic eruptions, the injection height of the emissions is of the order of a few hundred meters and is dominated by thermal plume rise. However, explosive eruptions have a considerable initial exit velocity, and the high thermal energy in the eruption plumes allows them to 
quickly reach high altitudes (greater than $10 \mathrm{~km}$ ). Generally the injection height depends on eruption type and meteorological conditions (e.g., the horizontal winds, humidity and thermal stratification) [Oberhuber et al., 1998]. For explosive eruptions characterized by a Volcanic Explosivity Index (VEI) [Newhall and Self, 1982] of 2-3, moderate scale, 20\% of volcanic plumes rise higher than $15 \mathrm{~km}, 60 \%$ rise above $10 \mathrm{~km}$, and $80 \%$ rise above $6 \mathrm{~km}$ [Halmer and Schmincke, 2003]. For the eruption of Mount Pinatubo in June 1991 (VEI 6, "colossal"), gas and particles were carried to an altitude of more than $30 \mathrm{~km}$ [McCormick et al., 1995]. Once the species have reached the stratosphere they are rapidly advected around the globe.

[5] Dispersion models can forecast the long-range transport of the emissions. However, one problem is the vertical transport in the eruption column which they cannot explicitly simulate. Thus, the vertical emission profile is needed as an input parameter, which must be determined by other means. Determining the emission height profile of a volcanic eruption is a challenge. In principle, it can be obtained by special models like the Active Tracer High Resolution Model (ATHAM) which can simulate the vertical transport of ash in the eruption column. However, they require accurate estimates of the mass flux of pyroclastic material and other information that is normally not available, especially not on a near real-time basis [Oberhuber et al., 1998; Textor et al., 2003].

[6] Measurements using aircraft [Mankin et al., 1992] and weather radar and lidar observations [Wang et al., 2008] can provide information on the plume height. However, not all locations are covered by such observations. Remote sensing observations from satellites can provide global coverage, but normally they only deliver total columns or poorly resolved vertical profiles. Also, many instruments operate from lowEarth orbits providing only one or two overpasses per day limiting the temporal resolution of the measurements. Other methods can potentially provide information on the $\mathrm{SO}_{2}$ vertical distribution in the lower troposphere by calculating a residual on the basis of $\mathrm{SO}_{2}$ columns from infrared (IR) and ultraviolet satellite retrievals [Carn et al., 2008]. Also recent studies using ultraviolet (UV) satellite data can retrieve effective plume heights [Yang et al., 2009a].

[7] A common technique to estimate the vertical emission profile for the purpose of volcanic plume forecasting involves trial-and-error fits between satellite observations of the total column of volcanic debris or gases and model results based on different assumptions of the emission height. For example, model trajectories can be used with satellite measurements of $\mathrm{SO}_{2}$ from the Ozone Monitoring Instrument (OMI), to fit trajectories at certain altitudes with the observations [Carn et al., 2008]. The disadvantage with this method is that the model runs and satellite data are matched "by eye." This is a subjective process that is time-consuming and can lead to errors.

[8] In this paper, we present the vertical emission height profile of $\mathrm{SO}_{2}$ derived through an analytical inversion method. $\mathrm{SO}_{2}$ alone is useful for tracking volcanic clouds. In situations where ash is not detectable owing to opaque signals, large water contents and cloud cover, the $\mathrm{SO}_{2}$ can be more easily observed by satellite sensors than ash. In a sheared atmosphere the ash and $\mathrm{SO}_{2}$ in eruption clouds may travel in different horizontal directions, but it is likely that the $\mathrm{SO}_{2}$ is accompanied by some ash. Thus, under the assumption that $\mathrm{SO}_{2}$ and ash are collocated, $\mathrm{SO}_{2}$ can serve as a proxy for volcanic ash and be employed to track the volcanic clouds. The $\mathrm{SO}_{2}$ is also important for geochemical and climate modeling in itself (e.g., for stratospheric chemistry, ozone depletion, climate studies).

[9] The inverse method has recently been developed by Eckhardt et al. [2008] and tested in a case study of the 30 September 2007 low-latitude eruption of the Jebel at Tair Volcano $\left(15.55^{\circ} \mathrm{N}, 41.83^{\circ} \mathrm{E}\right)$ located in the Red Sea. The Jebel at Tair eruption was an ideal test case because it provided excellent observation conditions for satellite remote sensing (a dry cloudless atmosphere) and very good coverage by such observations. For this paper, on the basis of Kristiansen [2009], the inverse method is tested for the high-latitude eruption of Kasatochi Volcano in August 2008. The observation conditions for this eruption were more difficult and, thus, provide a more demanding test case for the inverse method.

\section{Kasatochi Volcano, Alaska}

[10] Kasatochi Volcano $\left(52.17^{\circ} \mathrm{N}, 175.51^{\circ} \mathrm{W}\right)$ is a small $(2.7 \times 3.3 \mathrm{~km})$ unpopulated island volcano situated on the Aleutian Arc. The active stratovolcano reaches only $314 \mathrm{~m}$ high. From 7 to 8 August 2008 Kasatochi Volcano erupted with little warning after lying dormant for more than 200 years (see the Alaska Volcano Observatory Kasatochi Eruption Page, available at http://www.avo.alaska.edu/ activity/Kasatochi.php). The eruption emitted 1.2-2.5 Tg of $\mathrm{SO}_{2}$ to the atmosphere [e.g., Karagulian et al., 2010; Prata et al., 2010 ; Richter et al., 2009; Rix et al., 2008] (see also NASA's Volcanoes and Earthquakes Aleutian Islands' Kasatochi Volcano eruption pages, available at http://earthobservatory.nasa.gov/NaturalHazards/; hereinafter referred to as NASA (2008)), which is the largest $\mathrm{SO}_{2}$ mass loading since Chile's Hudson Volcano erupted in 1991. The eruption also injected about $0.3-0.7 \mathrm{Tg}$ of ash into the atmosphere [Corradini et al., 2010; Prata et al., 2010]. The ash particles affected aviation in Alaska but were settled out after a few days, while the $\mathrm{SO}_{2}$ dispersed throughout the Northern Hemisphere.

[11] The Alaska Volcano Observatory (AVO) reported that three distinct explosive eruptions occurred at Kasatochi at 2201 UTC on 7 August and 0150 and 0435 UTC on 8 August [Waythomas et al., 2008]. The first two events produced relatively ash-poor, but gas-rich eruption clouds that reached $\sim 14.5-16.5 \mathrm{~km}$. The third event generated an ash- and gas-rich plume that rose to about the same altitude, and was followed by about $17 \mathrm{~h}$ of continuous ash emission as determined from satellite data. Prata et al. [2010] show that the ash and $\mathrm{SO}_{2}$ erupted from Kasatochi were collocated and could be observed to travel together for at least 3 days following the 8 August eruptions, thus $\mathrm{SO}_{2}$ may serve as an appropriate proxy for ash in this case.

[12] Synoptic maps of geopotential heights of the pressure levels 1000 and $500 \mathrm{hPa}$ shortly after the first eruption, taken from the European Centre for Medium-Range Weather Forecasts (ECMWF) analysis, are shown in Figure 1. A lowpressure system was passing over the area in the hours of the eruptions, which generated a distinct circular shaped $\mathrm{SO}_{2}$ plume, as seen from the Atmospheric InfraRed Sounder 


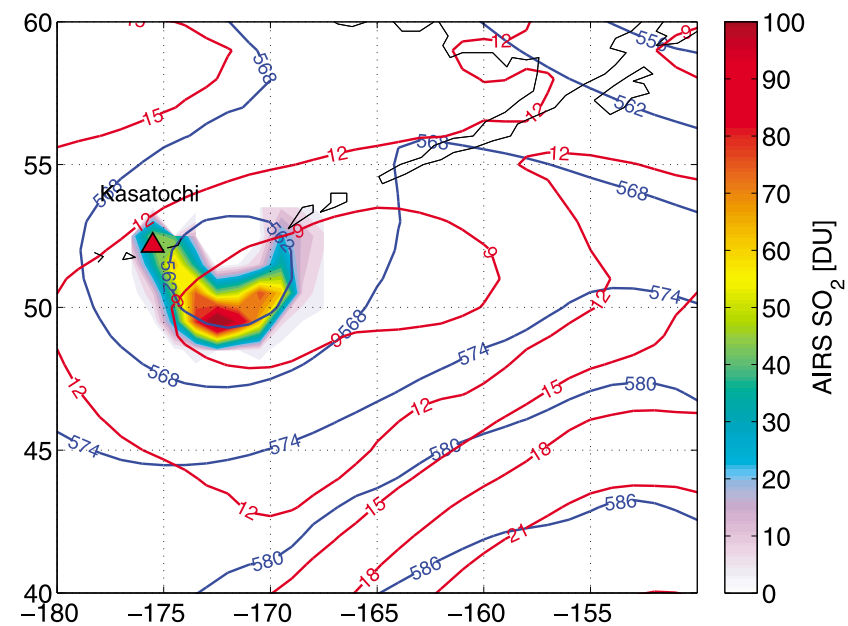

Figure 1. Geopotential height $\left(10^{1} \mathrm{~m}\right)$ in the area of the Kasatochi Volcano, on pressure levels $1000 \mathrm{hPa}$ (red lines) and $500 \mathrm{hPa}$ (blue lines) from the ECMWF analysis, on 8 August 2008 at 1200 UTC. Satellite measurements of $\mathrm{SO}_{2}$ total columns by AIRS on 8 August at 1341 UTC are shown in color shadings. The Kasatochi Volcano is marked by a red triangle.

(AIRS) satellite measurements. The thermal tropopause height around the Kasatochi Volcano, given by the ECMWF data, was about $10 \mathrm{~km}$. Given the reported injection height from AVO $(\sim 14.5-16.5 \mathrm{~km})$ the debris from the eruption penetrated into the stratosphere.

\section{Atmospheric Transport Modeling}

[13] In this study the Lagrangian particle dispersion model FLEXPART [Stohl et al., 1998, 2005] (see also http:// transport.nilu.no/flexpart) was used to simulate the transport of $\mathrm{SO}_{2}$ emitted by the eruption of Kasatochi Volcano. The model was first described and validated by Stohl et al. [1998] with data from continental-scale tracer experiments and is now used for a large range of applications, including simulating the dispersion of volcanic plumes [Prata et al., 2007; Eckhardt et al., 2008].

[14] FLEXPART calculates trajectories of "tracer particles" (not necessarily representing real particles, but infinitesimally small air parcels) as they are displaced by the winds. For this study, the model simulations were based on meteorological analysis data provided by ECMWF (see IFS Documentation, edited by P. W. White; available at http:// www.ecmwf.int). The global ECMWF model data has 91 vertical levels with a resolution of about $420 \mathrm{~m}$ near $12 \mathrm{~km}$, and $1^{\circ} \times 1^{\circ}$ horizontal resolution. A nest with higher resolution of $0.5^{\circ} \times 0.5^{\circ}$ was used for the area of interest (the eastern North Pacific region: $180-120^{\circ} \mathrm{W}, 40$ $\left.60^{\circ} \mathrm{N}\right)$. Analyses at $0000,0600,1200$, and $1800 \mathrm{UTC}$ as well as $3 \mathrm{~h}$ forecasts at intermediate times were used. We also made alternative FLEXPART simulations using input data from the National Centers for Environmental Prediction Global Forecast System (GFS) model with $0.5^{\circ} \times 0.5^{\circ}$ resolution at 26 pressure levels.

[15] Trajectories of $\mathrm{SO}_{2}$ tracer particles are calculated using the mean winds interpolated from the analysis fields as well as random motion representing turbulence [Stohl and Thompson, 1999]. For moist convective transport, FLEXPART uses the scheme of Emanuel and ŽivkovićRothman [1999], as implemented and tested in FLEXPART by Forster et al. [2007].

[16] In the atmosphere, $\mathrm{SO}_{2}$ is lost by reaction with the $\mathrm{OH}$ radical, dry deposition, and aqueous-phase chemical reactions. Monthly averaged three-dimensional $\mathrm{OH}$ concentration fields provided from the GEOS-CHEM model [Bey et al., 2001], were used to determine tracer mass loss by reaction with $\mathrm{OH}$. This process is more important in the troposphere than in the stratosphere. Aqueous-phase chemical reactions were not considered in the model simulations. Dry deposition of $\mathrm{SO}_{2}$ was calculated with the resistance method [Wesely and Hicks, 1977] using data from Wesely [1989] with updates.

[17] FLEXPART model runs were used as input to the inversion method to explore the sensitivity of downwind $\mathrm{SO}_{2}$ total columns to the altitude and mass of the initial emissions. Fifty releases were configured in vertically stacked emission layers of $500 \mathrm{~m}$ thickness between the model ground and $25 \mathrm{~km}$ above the volcano. In each of these layers, 300000 tracer particles with a unit mass were released uniformly along a vertical line source and subsequently tracked in the model atmosphere. Three different simulations were executed with particles released at the times of the eruption onsets as reported by AVO; on 7 August at 2201 UTC and on 8 August at 0150 and 0435 UTC. The simulation extended for 2 days after the eruption onset. Concentrations were calculated as hourly means throughout the simulation. The output grid was $0.5^{\circ} \times 0.5^{\circ}$ horizontally, with 9 vertical layers of $2 \mathrm{~km}$ resolution between $4 \mathrm{~km}$ and $22 \mathrm{~km}$, a single layer between the surface and $4 \mathrm{~km}$., and another layer from 22 to $50 \mathrm{~km}$. From this model output, gridded total atmospheric columns were calculated from the particle distribution using averaging kernels as described in section 4.4. The simulations can be viewed as sourcereceptor relationships which measure the sensitivity of a column value to the emission strength in each of the emission layers. Using these sensitivities and satellite observations of total $\mathrm{SO}_{2}$ columns, the inversion finally yields estimates of the actual mass injected in each of the layers above the volcano.

[18] After applying the inversion method and obtaining the estimated emission profile of $\mathrm{SO}_{2}$, a longer FLEXPART simulation of the transport was performed. This simulation extended over one month following the eruption onset and was used for validation of the estimated profile by comparison with independent observations.

\section{Remote Sensing Data}

[19] Several satellite instruments made measurements of the $\mathrm{SO}_{2}$ released by the eruption of Kasatochi Volcano over the days following the eruption. For this study we have utilized both ultraviolet and infrared satellite retrievals of $\mathrm{SO}_{2}$. The instruments measuring in the ultraviolet spectral region include the Global Ozone Monitoring Experiment-2 (GOME-2) and OMI, while AIRS provides infrared measurements.

[20] All of the instruments deliver total or partial column measurements with little vertical resolution. The infrared 
retrievals provide partial column measurements owing to very low sensitivity to $\mathrm{SO}_{2}$ in the moist lower troposphere, while the ultraviolet retrievals can detect $\mathrm{SO}_{2}$ down to the ground. Depending on which altitude the $\mathrm{SO}_{2}$ is located, the assumed a priori satellite profile and on other factors such as the temperature and humidity profiles, the different retrievals may yield different column amounts. One big advantage of the AIRS retrievals is the ability to make observations also during nighttime, while the ultraviolet measuring instruments are restricted to daytime observation. All satellite data were resampled to the FLEXPART $0.5^{\circ} \times 0.5^{\circ}$ output grid, and observations larger or equal to zero were used in the inversion procedure.

[21] In addition, the Infrared Atmospheric Sounder Interferometer (IASI) provided measurements of the eruption of Kasatochi which were utilized by Karagulian et al. [2010] to retrieve a coarse-resolution vertical profile of $\mathrm{SO}_{2}$. This profile has been applied to our inversion algorithm as a priori information.

\subsection{GOME-2}

[22] The GOME-2 instrument is a UV/visible spectrometer covering the wavelength region of 240-790 $\mathrm{nm}$ at a moderate spectral resolution of $0.2-0.4 \mathrm{~nm}$ with a groundpixel size of $80 \times 40 \mathrm{~km}^{2}$ over most of the globe [Munro et al., 2006]. With its large swath, GOME-2 provides daily coverage at latitudes beyond $45^{\circ}$ and full global coverage after 3 days. For this study, $\mathrm{SO}_{2}$ retrievals were performed with a variant of the Differential Optical Absorption Spectroscopy (DOAS) method taking into account the nonlinearity introduced by the large $\mathrm{SO}_{2}$ absorption during this eruption. Using the spectral window of 312.5-327 nm, tabulated slant optical depths (SODs) of $\mathrm{SO}_{2}$ and ozone together with a closure polynomial and a correction for the effect of Raman scattering were fitted to the optical thickness derived from the measured Earth-shine and solar irradiance. For the initial iteration, $\mathrm{SO}_{2}$ slant optical depths for an a priori of 1 Dobson Unit $\left(1 \mathrm{DU}=2.69 \times 10^{16}\right.$ molecules $\left./ \mathrm{cm}^{2}\right) \mathrm{SO}_{2}$ vertical column were used. Depending on the retrieved column, a new SOD was selected from the lookup table on the basis of a more appropriate a priori and a new DOAS retrieval was performed. This procedure was repeated until closure was found between the retrieved and the a priori column. This iterative retrieval approach is necessary as $\mathrm{SO}_{2}$ becomes a strong absorber in the UV at the high column amounts experienced during the Kasatochi eruption. Ignoring this effect leads to strong underestimation of the total column. Similar approaches have been proposed by Richter et al. [2006] and Yang et al. [2009b] for situations with much less $\mathrm{SO}_{2}$. After the main retrieval, each orbit was post processed to remove a small latitudinal offset $(0.1-0.5 \mathrm{DU})$ in the $\mathrm{SO}_{2}$ columns by applying a median filter over $\pm 10^{\circ}$ latitude. The magnitude of the corrections is negligible compared to the columns discussed here. Details on the retrieval can be found in the work of Richter [2009].

[23] As discussed in the work of Yang et al. [2007], both the vertical distribution of $\mathrm{SO}_{2}$ and the ozone column have an impact on the retrieved $\mathrm{SO}_{2}$ column. Here, the U.S. standard atmosphere has been used for pressure, temperature and $\mathrm{O}_{3}$ while for the $\mathrm{SO}_{2}$ a cloud of $1 \mathrm{~km}$ thickness centered at an altitude of $10.5 \mathrm{~km}$ was assumed. The only parameter varied during the iteration was the amount of $\mathrm{SO}_{2}$ in the layer. These simplified assumptions together with the impact of clouds and aerosols which have not been accounted for lead to a relatively large uncertainty of the $\mathrm{SO}_{2}$ columns retrieved in the Kasatochi cloud. We estimate this uncertainty to be of the order of $10-20 \%$ in the volcanic cloud while the noise level outside the cloud is better than $1 \mathrm{DU}$ for individual measurements and should be comparable within the cloud. The uncertainties in the retrieval are thus dominated by the assumed $\mathrm{SO}_{2}$ layer altitude and cloud effects. Maximum $\mathrm{SO}_{2}$ mass loadings for the eruption of Kasatochi were found to be up to about $2.5 \mathrm{Tg}$ from GOME-2 data on the first day after the eruption with an exponential decline over the following month [Richter et al., 2009].

\subsection{OMI}

[24] The OMI instrument on board the Earth Observing System (EOS)-Aura satellite was designed principally for measuring global ozone, but with secondary goals of measuring other trace gases, including $\mathrm{SO}_{2}$. It measures solar backscattered radiation in the UV between 270 and $365 \mathrm{~nm}$. The daytime equator crossing time is 1045 UTC, the nadir pixel size is $13 \times 24 \mathrm{~km}^{2}$ and the swath width is $2600 \mathrm{~km}$ which provides once-daily global coverage.

[25] $\mathrm{SO}_{2}$ column data from OMI are produced using the Band Residual Difference (BRD) algorithm [Krotkov et al., 2006] and the Linear Fit (LF) algorithm [Yang et al., 2007]. For this study we used the operational product estimate of the column density of $\mathrm{SO}_{2}$ for the upper tropospheric and stratospheric $\mathrm{SO}_{2}$ (ColumnAmountSO2 STL). The retrieval used for determining $\mathrm{SO}_{2}$ from OMI exploits the $\mathrm{SO}_{2}$ absorption features between 310 and $340 \mathrm{~nm}$. The effect of absorption by ozone in the same spectral region, and also effects of Rayleigh multiple scattering and the "Ring effect" have been accounted for in the algorithm. For large $\mathrm{SO}_{2}$ columns (greater than $100 \mathrm{DU}$ ), such as for Kasatochi, the LF retrieval error increases and the algorithm underestimates the true $\mathrm{SO}_{2}$ amount by up to $50 \%$. The overall uncertainties of the OMI retrievals for Kasatochi are assumed to be in the same order as the GOME-2 uncertainties [Yang et al., 2007; $\mathrm{K}$. Yang, personal communication, 2009]. $\mathrm{SO}_{2}$ mass loadings for the eruption of Kasatochi were found to be about $1.4 \mathrm{Tg}$ from OMI (see NASA (2008) and http://earthobservatory. nasa.gov/IOTD/view.php?id=8998).

\subsection{AIRS}

[26] The AIRS instrument on board the EOS-Aqua polar orbiting satellite was able to clearly detect the $\mathrm{SO}_{2}$ cloud from Kasatochi for about 1 week and with less ability in the following weeks as the cloud was diluted and transported over Europe and eastward toward Russia [Prata et al., 2010]. The infrared retrievals have less sensitivity than the UV retrievals and thus AIRS cannot detect the $\mathrm{SO}_{2}$ for as long as OMI or GOME-2. The AIRS instrument has high spectral resolution and is operating at infrared wavelengths between 3.7 and $15.4 \mu \mathrm{m}$ [Chahine et al., 2006]. The swath width is $\pm 49^{\circ}$ from nadir producing nadir pixels with dimensions $15 \times 15 \mathrm{~km}^{2}$, increasing to $18 \times 40 \mathrm{~km}^{2}$ at the swath edge. The $\mathrm{SO}_{2}$ partial column abundances were determined by use of the retrieval scheme developed by Prata and Bernardo [2007]. The algorithms for determining 
Table 1. Estimates of Total $\mathrm{SO}_{2}$ Mass Emitted by the Eruption of Kasatochi Volcano ${ }^{\mathrm{a}}$

\begin{tabular}{ccl}
\hline Satellite Retrieval & Total Mass $\mathrm{SO}_{2}$ & \multicolumn{1}{c}{ Reference } \\
\hline GOME-2 & $\sim 2.5 \mathrm{Tg}$ & Richter et al. $[2009]$ \\
OMI & $\sim 1.4 \mathrm{Tg}$ & NASA (2008) \\
AIRS & $\sim 1.2 \mathrm{Tg}$ & Prata et al. [2010], this paper \\
IASI & $\sim 1.7 \mathrm{Tg}$ & Karagulian et al. [2010] \\
\hline
\end{tabular}

${ }^{\mathrm{a}}$ For different satellite retrievals using the ultraviolet sensors Global Ozone Monitoring Experiment-2 (GOME-2) and Ozone Monitoring Instrument (OMI), and the infrared sensors Atmospheric InfraRed Sounder (AIRS) and Infrared Atmospheric Sounder Interferometer (IASI).

$\mathrm{SO}_{2}$ from AIRS exploit the strong $\mathrm{SO}_{2}$ antisymmetric absorption feature near $7.3 \mu \mathrm{m}$, but because water vapor also absorbs strongly across this band, the retrievals are restricted to regions of the atmosphere that are relatively dry; that is, the upper troposphere (heights greater than $3 \mathrm{~km}$ ) and lower stratosphere. This means that whenever $\mathrm{SO}_{2}$ and water vapor are collocated it is difficult to quantify the $\mathrm{SO}_{2}$. However, the two-step retrieval procedure devised by Prata and Bernardo [2007] accounts for both $\mathrm{SO}_{2}$ and water vapor simultaneously. AIRS error estimates for an individual pixel are at worst \pm 6 DU, and typically \pm 3 DU [Prata and Bernardo, 2007]. For $\mathrm{SO}_{2}$ clouds that are high and thick, it is possible for the IR bands to saturate and an upper limit on $\mathrm{SO}_{2}$ detection is reached. Examination of the AIRS IR spectra for Kasatochi suggests that this did occur in some places of the first AIRS pass (8 August at 1341 UTC), but since we use several other satellite data where saturation did not occur, we assume that this is not significance for the inversion results.

[27] Maximum Upper Troposphere/Lower Stratosphere (UTLS) mass loadings were found to be $\sim 1.2 \mathrm{Tg}$ from AIRS [Prata et al., 2010], which is lower than that found using ultraviolet measurements. The difference is mostly due to the lower sensitivity to pixels with low $\mathrm{SO}_{2}$ amounts (less than $3 \mathrm{DU}$ ) and the narrow AIRS swath width, which sometimes excluded portions of the $\mathrm{SO}_{2}$ cloud. Table 1 gives an overview of the estimates of total mass emitted from the eruption of Kasatochi, derived from various satellite retrievals.

\subsection{Height Sensitivity}

[28] The satellite retrievals depend on a number of factors such as the wavelength region of the measurements, the atmospheric temperature profile and the vertical distributions of all absorbing gases. This implies that the magnitude of the observed $\mathrm{SO}_{2}$ signal does not only depend on the total $\mathrm{SO}_{2}$ amount in the atmosphere but also on its vertical distribution which cannot be obtained from the measurements themselves. Only in very recent studies, UV satellite data can be used to retrieve effective $\mathrm{SO}_{2}$ altitudes directly from the measurement data [Yang et al., 2009a]. Generally, in the satellite retrievals of $\mathrm{SO}_{2}$ a priori assumptions have to be made about the height of the $\mathrm{SO}_{2}$ cloud. In regard to this, the weighting function and averaging kernel are used as described by Rodgers [2000] and more specifically by Eskes and Boersma [2003]. The weighting function represents the sensitivity of the radiance contribution from a layer at a certain height level to the total radiance sensed by the satellite. The averaging kernel is the sensitivity of the retrieval to the true state, or more specifically a vector, describing sensitivity of the column $\mathrm{SO}_{2}$ retrieval to changes in $\mathrm{SO}_{2}$ partial columns at a given altitude. The averaging kernel can be used for direct comparisons between model data and satellite column observations [Eskes and Boersma, 2003]. We use the averaging kernels shown in Figure 2 to sample the FLEXPART $\mathrm{SO}_{2}$ concentration vertical profile with the averaging kernel of the corresponding satellite retrieval.

[29] For the AIRS satellite data, we use an averaging kernel for a band-averaged channel at around $7.3 \mu \mathrm{m}$ for a perturbed atmosphere with a layer of $\mathrm{SO}_{2}$ present at $15 \mathrm{~km}$. For normal atmospheric conditions, the sensitivity is greatest in the upper to midtroposphere and least in the lowest and highest parts of the atmosphere as seen in Figure 2. Eckhardt et al. [2008] describes in more detail the sensitivity of the infrared retrievals to the height of the $\mathrm{SO}_{2}$ cloud.

[30] For UV retrievals, the averaging kernel depends also on surface albedo and $\mathrm{O}_{3}$ column, but it is in particular the atmospheric $\mathrm{SO}_{2}$ profile that is problematic in the presence of large $\mathrm{SO}_{2}$ amounts as the atmosphere below a thick $\mathrm{SO}_{2}$ layer is basically shielded from the satellite view. For GOME-2, we approximate the averaging kernel by a single calculation performed at $317 \mathrm{~nm}$ for a UV surface albedo of 0.03 and a $1 \mathrm{~km}$ thick $\mathrm{SO}_{2}$ column of 200 DU centered at $10.5 \mathrm{~km}$. For OMI retrievals, the sensitivity to the height of the $\mathrm{SO}_{2}$ is explained by Yang et al. [2007]. For this study we have used an averaging kernel for a cloud-free pixel with a surface reflectivity of 0.1 and a prescribed $\mathrm{SO}_{2}$ profile in Umkehr layer 3 [see Yang et al., 2007, Figure 7]. The difference in shape between the OMI and GOME-2 averaging kernel is a result of the different $\mathrm{SO}_{2}$ columns assumed, with small $\mathrm{SO}_{2}$ loadings assumed for the OMI operational product and large $\mathrm{SO}_{2}$ amounts for the GOME-2 retrievals.

[31] Ideally, one should use a different averaging kernel for each pixel to account for regional variability in observing conditions. However, in this study, only one typical averaging kernel for each of the three satellite data sets was employed. Using fixed, typical averaging kernels adds unspecified biases and uncertainties in the current application of the inversion method and this will be subject for future improvements of our method.

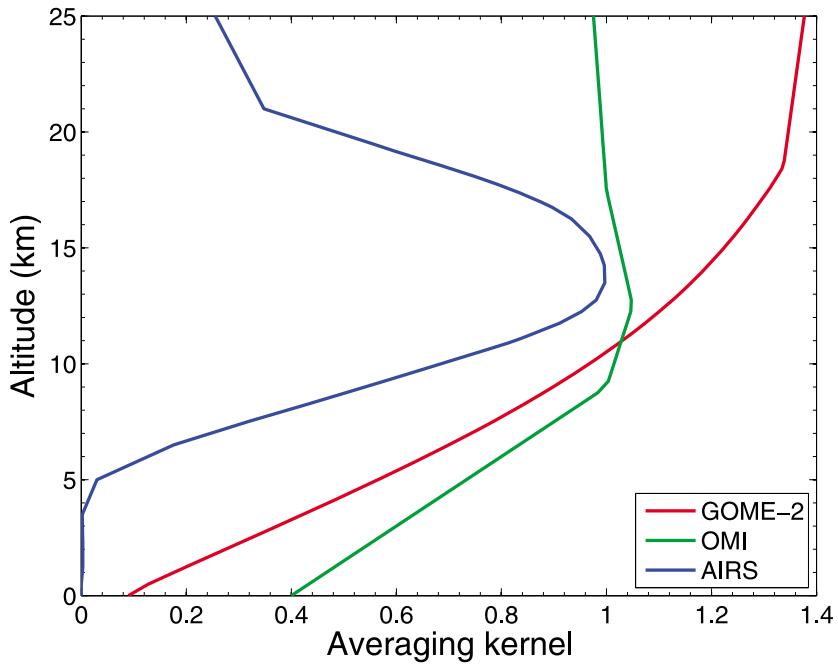

Figure 2. Averaging kernels for the GOME-2, OMI, and AIRS retrievals of $\mathrm{SO}_{2}$. 


\subsection{Lidar Measurements}

[32] The Kasatochi cloud was observed with both groundbased and satellite-based aerosol lidar instruments. The CloudAerosol Lidar with Orthogonal Polarization (CALIOP) on board the Cloud-Aerosol Lidar and Infrared Pathfinder Satellite Observation (CALIPSO) satellite made measurements of the Kasatochi eruption cloud multiple times in the weeks after the eruption. CALIPSO was launched in 2006 and flies as a part of the A-train at $705 \mathrm{~km}$ altitude in a $98^{\circ}$ inclination Sun-synchronous polar orbit. The equatorcrossing time is at 1330 local solar time, with a 16 day repeat cycle. CALIOP provides profiles of backscatter at $532 \mathrm{~nm}$ and $1064 \mathrm{~nm}$, as well as the degree of the linear polarization of the $532 \mathrm{~nm}$ signal [Winker et al., 2007]. It is a nadir-only looking instrument $(60 \mathrm{~m}$ pixel size spaced $330 \mathrm{~m}$ apart) providing a curtain of measurements with a vertical resolution of 30-300 m. We have utilized the primary level 1 data products of total attenuated backscatter at $532 \mathrm{~nm}$ and $1064 \mathrm{~nm}$. The attenuated backscatter profile is the calibrated, range-corrected, laser energy normalized, baseline-subtracted lidar return signal (see Hostetler et al. [2006] for more details).

[33] The Dalhousie Raman Lidar at Halifax, Nova Scotia $\left(44.6^{\circ} \mathrm{N}, 63.6^{\circ} \mathrm{W}\right)$, Canada, observed the debris from Kasatochi for several months after the eruption. The observations and the instrument is described by Bitar et al. [2010]. It employs a frequency-doubled Nd:YAG laser transmitting pulses of $532 \mathrm{~nm}$ light into the atmosphere at a frequency of $20 \mathrm{~Hz}$, and a $25 \mathrm{~cm}$ telescope with photomultipliers and fast counting electronics in the receiver. Profiles of the aerosol extinction coefficient are derived from the measured elastic lidar signals using the Klett inversion technique [Klett, 1981]. A constant aerosol extinction-to-backscatter (lidar) ratio of $40 \mathrm{sr}$ was assumed, which is consistent with the lidar ratio observed for stratospheric aerosols after volcanic eruptions [Jäger and Deshler, 2002, and references therein].

[34] The AWIPEV station, operated by AWI (AlfredWegener-Institute for Polar and Marine Research) and IPEV (Institut polaire Français Paul-Emile Victor) in Ny-Ålesund $\left(78.9^{\circ} \mathrm{N}, 11.9^{\circ} \mathrm{E}\right)$ on Svalbard observed the Kasatochi cloud using the Koldewey-Aerosol-Raman-Lidar (KARL). KARL is a backscatter-Raman lidar determining the concentration of aerosols in the atmosphere using a pulsed $\mathrm{Nd}$ :YAG laser which emits beside the $1064 \mathrm{~nm}$ fundamental laser line the frequency doubled $(532 \mathrm{~nm})$ and tripled $(355 \mathrm{~nm})$ laser lines with a pulse repetition frequency of $50 \mathrm{~Hz}$ (for further details, see Hoffmann et al. [2010]). The aerosol backscatter coefficient is calculated with the Klett algorithm [Klett, 1981] on the basis of 10 min integrated profiles with a vertical resolution of $60 \mathrm{~m}$.

[35] The lidar measurements were used to validate the height of the simulated $\mathrm{SO}_{2}$ cloud. The aerosol extinction coefficient is roughly proportional to the total aerosol mass and was used as a proxy of the sulphate concentrations in the atmosphere. Aerosols are formed by the conversion of $\mathrm{SO}_{2}$ to sulphate and the validation was done by comparing the lidar measurements with the $\mathrm{SO}_{2}$ concentration simulated by FLEXPART. The comparison is qualitative as aerosol extinction coefficient and concentration of $\mathrm{SO}_{2}$ are two different quantities. However, because one is formed from the other, it is expected that $\mathrm{SO}_{2}$ and aerosols are at the same altitude.

\section{Inversion Algorithm}

[36] The inversion method used in this study is based on the work of Seibert [2000] and has been expanded and described recently by Eckhardt et al. [2008]. They improved it to allow for an a priori for the unknown sources, a Bayesian formulation considering uncertainties for the a priori sources and the observations and an iterative algorithm for ensuring a solution with only positive values. A major advantage of this algorithm is that it provides an almost entirely analytical solution of the optimization problem, making it very fast and reliable.

[37] Like in other inverse problems [e.g., Menke, 1984], we have observations that depend on a number of control variables through a physical process which can be quantitatively simulated. Here, the observations are sets of (weighted) $\mathrm{SO}_{2}$ column values, the control variables are the $\mathrm{SO}_{2}$ emission rates as a function of height (and possibly time) at discrete intervals, and the physical process is the transport, diffusion and transformation of $\mathrm{SO}_{2}$ in the atmosphere.

[38] The optimum solution (values of the control parameters) is defined as leading to the best agreement between observed and simulated values. "Best" agreement is measured as the sum of the squared differences. Different to the ordinary Root Mean Square Errors (RMSE), however, we are taking into account uncertainty variances as weights for forming the sum. This leads to a "most likely" solution in the statistical sense, provided at least that the errors are normally distributed and independent.

[39] If there were sufficient observation data and not too many unknown control variables, this would be enough to obtain a meaningful solution to our problem. Minimizing the cost function consisting of the weighted squared errors yields a linear system of equations that can be solved analytically with standard linear algebra methods and software tools. However, if we construct the vector of unknowns as a simple stack of emissions in equidistant vertical layers, we could easily find that some parts; for example, close to the ground (low sensitivity of the satellite retrievals) or at high levels near or above the top of the eruption column (small wind shear), are not well constrained by observations. This could render the solution unstable, even if the number of known variables exceeds well the number of unknowns, leaving us with a so-called ill-conditioned inverse problem. To prevent this, some form of a priori knowledge has to be added.

[40] In the method used here, two forms of a priori knowledge are used. One is a prescribed estimate of the emission profile shape (typically very smooth, possibly vertically constant) together with an uncertainty (usually formulated as a fraction of the first-guess estimate). The other is the assumption that the vertical profile is not fluctuating strongly from layer to layer, mathematically expressed as a small absolute value of the second derivative. Both assumptions provide additional terms to be added to the cost function and can be formulated as linear operators on the vector of unknowns. Thus, we can still proceed with the same standard solution method. The mathematical formalism would allow negative values to occur in the solution. To render the solution more physically meaningful, we use an iterative process 
a)

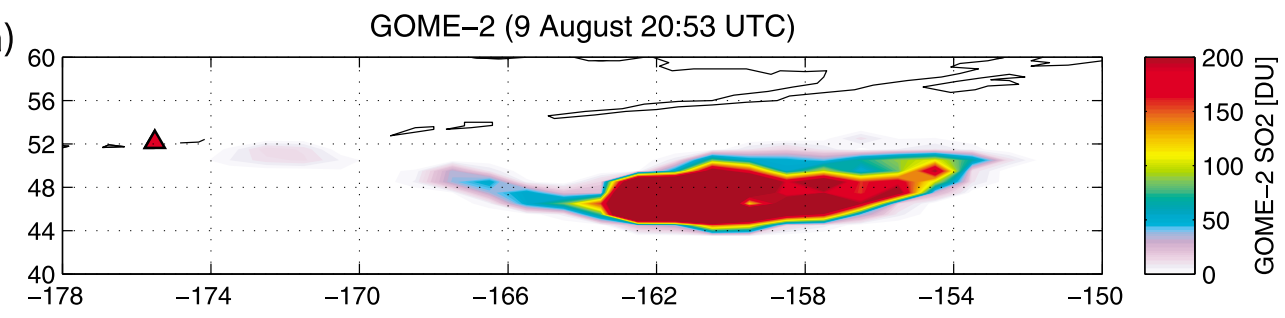

b)

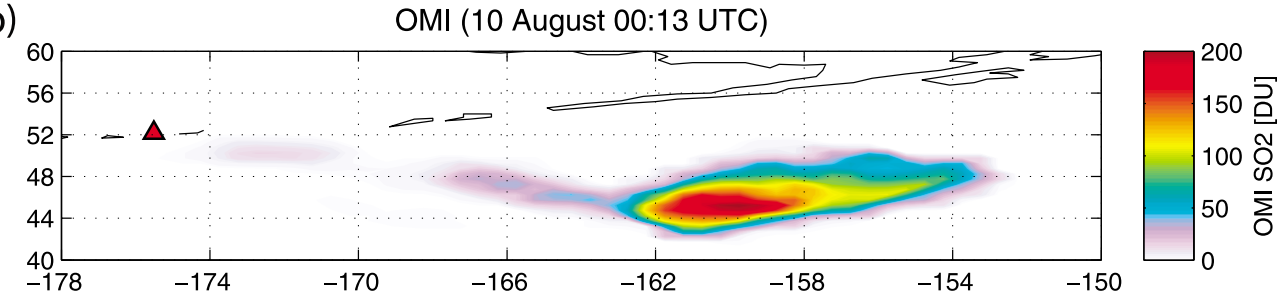

c)

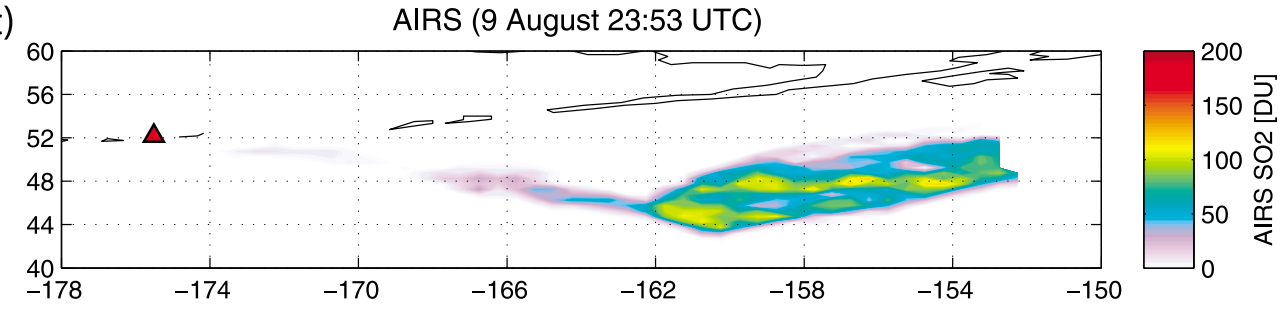

Figure 3. $\mathrm{SO}_{2}$ columns retrieved from (a) GOME-2, (b) OMI, and (c) AIRS measurements on 9-10 August 2008. The Kasatochi Volcano is marked by a red triangle.

to reduce the uncertainty of the first guess where the solution is negative until the resulting solution is not negative.

[41] All the mathematical details can be found in the work of Eckhardt et al. [2008]. What remains is the proper specification of the a priori profile and the uncertainties (weights). For this study, the a priori emissions were based on the shape of a coarse-resolution IASI $\mathrm{SO}_{2}$ profile estimated by Karagulian et al. [2010], which shows a broad maximum centered around $12 \mathrm{~km}$. The total mass of the a priori profile was specified to $1.3 \mathrm{Tg}$, which is in agreement with the minimum of the satellite emission estimates (see Table 1). The a priori uncertainties were chosen to allow substantial corrections to the initial profile (see Figures 4 and 6).

[42] The observation error should contain not only the uncertainty of the retrieved $\mathrm{SO}_{2}$ columns but rather be standard misfit between the observations and the model results. Because detailed error statistics are lacking, we assumed for the UV satellite data, an error of $20 \%$ of the individual pixel value plus $3 \mathrm{DU}$, giving a minimum of $3 \mathrm{DU}$ uncertainty for all pixels. For AIRS, a $30 \%+3$ DU uncertainty was chosen on the basis of the instrument's poorer sensitivity. The algorithm presently does not give an explicit estimate of the uncertainty of the solution. However, we examine its uncertainty by performing multiple inversions with different data sets and model results.

\section{Results and Discussion}

\subsection{Comparison of Satellite Data}

[43] $\mathrm{SO}_{2}$ column amounts retrieved from GOME-2, OMI and AIRS $\sim 2$ days after the eruption, between 2053 UTC on 9 August and 0013 UTC on 10 August are shown in Figure 3, for one swath per satellite sensor. The cloud has mainly drifted southeastward from the volcano over the Pacific Ocean. The $\mathrm{SO}_{2}$ distributions obtained from the three instruments are qualitatively similar, but the absolute values vary. For instance, the maximum GOME-2 and OMI columns are about four times larger and two times larger, respectively, than the maximum AIRS column.

[44] The reasons for the discrepancies between the different satellite data sets are not entirely clear. However, since the sensitivity to pixels with small $\mathrm{SO}_{2}$ amounts (less than $3 \mathrm{DU}$ ) is low for AIRS, and also that AIRS retrievals give only partial $\mathrm{SO}_{2}$ columns, with $\mathrm{SO}_{2}$ in the lower troposphere not being captured, a negative bias of the AIRS columns was expected. Also since the GOME-2 retrieval accounts for nonlinearities in the absorption and light path, this results in higher $\mathrm{SO}_{2}$ values than for OMI. It is established that OMI standard linear fit (LF) algorithm underestimates true column $\mathrm{SO}_{2}$ amounts when the $\mathrm{SO}_{2}$ loading is larger than $\sim 100 \mathrm{DU}$ [Yang et al., 2009b], which is the case of the Kasatochi eruption.

[45] It is clear that the biases between the different satellite data sets will cause problems when they are used jointly in the inversion procedure. Ideally, one should apply bias corrections before using these data for the inversions. However, it is not clear which data set should best serve as a reference and the factors determining the biases are not completely understood. Furthermore, the biases cannot easily be described with constant scaling factors. Therefore, we have used the satellite data without bias corrections and will pursue this in the future. 


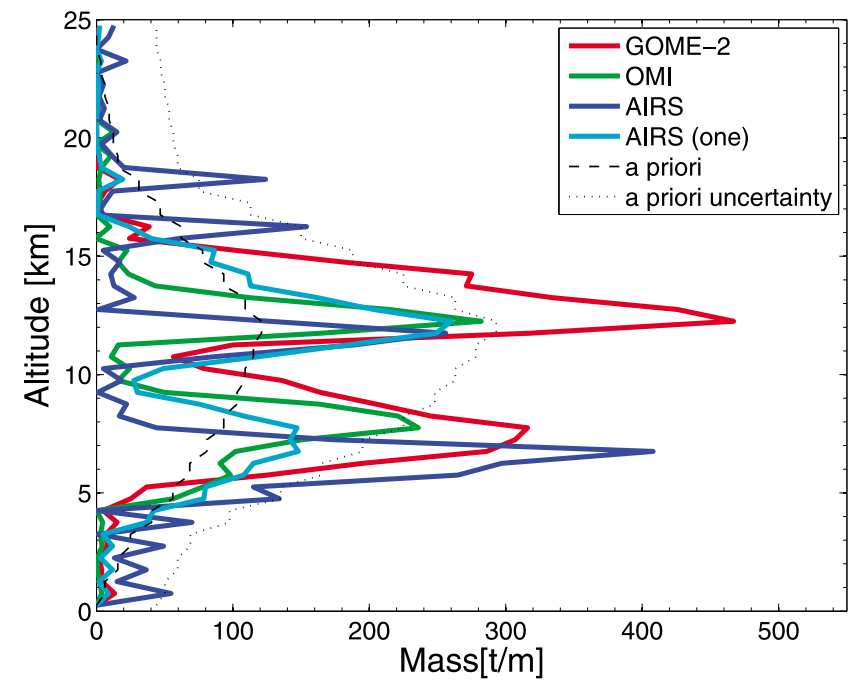

Figure 4. Inversion results from the 7 August 2008, 2201 UTC, assumed eruption time using satellite data from one instrument at a time: GOME-2 (red line), OMI (green line), and AIRS (blue line). The "AIRS (one)" profile is the inversion result when using only one AIRS satellite overpass on 9 August at 2353 UTC. ECMWF meteorological data were used for driving the FLEXPART simulations used for these inversions.

\section{2. $\mathrm{SO}_{2}$ Emission Height Profiles}

[46] Satellite data for up to 2 days after the eruption were used for the inversions. During that time interval, seven, two and four overpasses over the Kasatochi $\mathrm{SO}_{2}$ cloud were available for AIRS, OMI and GOME-2, respectively. In addition to using three different satellite data sets, inversions were performed for three different assumed eruption times, 2201 UTC on 7 August and 0150 and 0435 UTC on 8 August, corresponding to the eruption times reported by AVO. For each inversion we assume that all $\mathrm{SO}_{2}$ mass was emitted at one single eruption time. This is because we lack information on how much $\mathrm{SO}_{2}$ was likely emitted during each eruption, and it is possible that most of the $\mathrm{SO}_{2}$ was actually emitted during a single eruption. This approximation may yield inaccuracies, however as the time intervals between the eruptions are not very long, and the wind profiles at Kasatochi did not change much over the interval that the eruptions occurred, this approach is assumed valid. Furthermore we used two different meteorological input data sets from ECMWF and GFS, for driving the FLEXPART simulations used for the inversion.

[47] Figure 4 shows the results from the inversions for the 2201 UTC assumed eruption time using satellite data from one instrument at a time, and using ECMWF data for the model simulation. Generally, the emission profiles show that the eruption of Kasatochi resulted in large emissions of $\mathrm{SO}_{2}$ both in the middle and upper troposphere $(5-10 \mathrm{~km})$ as well as in the lower stratosphere $(10-15 \mathrm{~km})$, with two strong emission peaks at $\sim 7 \mathrm{~km}$ and $\sim 12 \mathrm{~km}$. Smaller emissions are found up to $\sim 20 \mathrm{~km}$. The largest stratospheric peak extends up to about $15-17 \mathrm{~km}$ which corresponds to the reports from AVO indicating emissions up to $14.5-16.5 \mathrm{~km}$ [Waythomas et al., 2008]. This stratospheric emission profile looks rather symmetric around peak altitude, which could be due to the relatively coarse vertical resolution of $500 \mathrm{~m}$, together with the smoothness condition of the inversion algorithm. On average, $\sim 50 \%$ of the total mass is injected above the thermal tropopause at $10 \mathrm{~km}$.

[48] The strength of the two largest emission peaks depends on the satellite data set used. The inversion with GOME-2 data (red line in Figure 4) gives the largest stratospheric peak, and also the largest total $\mathrm{SO}_{2}$ mass of $2.4 \mathrm{Tg}$. The OMI profile (green line in Figure 4) is similar but with reduced emission peaks and a total $\mathrm{SO}_{2}$ mass of $1.1 \mathrm{Tg}$. The AIRS profile (blue line in Figure 4) with a total $\mathrm{SO}_{2}$ mass of $1.5 \mathrm{Tg}$, shows a strong $\sim 7 \mathrm{~km}$ emission peak, a smaller stratospheric peak around $12 \mathrm{~km}$, and also more emissions above $15 \mathrm{~km}$. The anomalous peaks below $4 \mathrm{~km}$ are probably due to the poor sensitivity of AIRS in the lower troposphere.

[49] The total $\mathrm{SO}_{2}$ masses derived from the different AIRS overpasses were strongly fluctuating, partly because there were few AIRS overpasses which covered the whole $\mathrm{SO}_{2}$ cloud. The inversion method can work with partial satellite data, where only a part of the cloud is visible, but the constraints on the emissions will be lowered for those heights leading to the unobserved portions of the cloud. Only two of the seven AIRS overpasses captured the whole $\mathrm{SO}_{2}$ cloud, and only for the overpass on 9 August at 2353 UTC (see Figure 3), was the total mass within the same range $(\sim 1 \mathrm{Tg})$ as the GOME-2 and OMI total masses. Inversions were performed also using this overpass only (turquoise line in Figure 4) to investigate the sensitivity to the amount of satellite data used in the inversion. The good agreement with the profiles based on more satellite data demonstrates that the inversion can perform well when only one satellite overpass is used.

[50] Subsequently, inversions were performed for all the three satellite data sets combined, and also for each of the three eruption times and for each of the two meteorological input data types.

[51] A posteriori model values were calculated as the sensitivities multiplied with the estimated profile and represent the model values based on the estimated profile rather than the a priori profile. To compare the performance of the various inversions, we calculated Pearson correlation coefficients between the observations and the a posteriori model values, and RMSE as summarized in Table 2. While correlation coefficients and RMSE are only two of many possibilities to quantitatively describe how well the observations can be fitted by the model using the inverted vertical emission profile, they provide a simple means to compare and rank the various simulations. Notice that the sum of squared errors is also the largest term in the cost function used for the inversion [see Eckhardt et al., 2008]. When using the AIRS data, the correlation is lower for the inversions using the whole AIRS satellite data set (values in brackets in Table 2) compared to inversions using only the 9 August AIRS overpass. Therefore, for AIRS we chose to use only the one overpass for the remainder of this study.

[52] The bold, values in Table 2 indicate the three eruption times for which each meteorological data set yielded the highest correlations and lowest RMSE: ECMWF data for 2201 UTC and GFS data for 0150 UTC and 0435 UTC, respectively. It can also be seen that correlation coefficients 
Table 2. Summary of All Inversions Performed Using Different Meteorological Input Data, Different Satellite Data, and Three Eruption Times ${ }^{\mathrm{a}}$

\begin{tabular}{|c|c|c|c|c|c|c|c|}
\hline \multirow[b]{3}{*}{ Model Input Data } & \multirow[b]{3}{*}{ Satellite Data } & \multicolumn{6}{|c|}{ Eruption Times } \\
\hline & & \multicolumn{2}{|c|}{7 August, 2201 UTC } & \multicolumn{2}{|c|}{8 August, 0150 UTC } & \multicolumn{2}{|c|}{8 August, 0435 UTC } \\
\hline & & $\mathrm{r}$ & RMSE & $\mathrm{r}$ & RMSE & $\mathrm{r}$ & RMSE \\
\hline \multirow[t]{4}{*}{ ECMWF } & GOME-2 & 0.65 & 2.72 & 0.62 & 2.94 & 0.59 & 3.09 \\
\hline & OMI & 0.64 & 1.02 & 0.63 & 1.08 & 0.60 & 1.17 \\
\hline & AIRS & $0.69(0.31)$ & $0.72(0.96)$ & $0.65(0.28)$ & $0.80(1.01)$ & $0.62(0.21)$ & $0.84(1.08)$ \\
\hline & all & $\mathbf{0 . 6 2}(0.41)$ & $1.93(2.04)$ & $0.60(0.41)$ & $2.07(2.13)$ & $0.56(0.37)$ & $2.22(2.26)$ \\
\hline \multirow[t]{4}{*}{ GFS } & GOME-2 & 0.61 & 2.82 & 0.69 & 2.74 & 0.67 & 2.97 \\
\hline & OMI & 0.62 & 1.03 & 0.69 & 0.98 & 0.69 & 1.01 \\
\hline & AIRS & $0.66(0.42)$ & $0.77(0.91)$ & $0.56(0.32)$ & $0.88(0.99)$ & $0.55(0.30)$ & $0.90(1.04)$ \\
\hline & all & $0.57(0.46)$ & $1.98(1.98)$ & $0.62(0.42)$ & $1.99(2.08)$ & $0.60(0.45)$ & $2.07(2.16)$ \\
\hline
\end{tabular}

\footnotetext{
${ }^{a}$ Here $r$ is the Pearson correlation coefficient between the observations and the a posteriori model values, and RMSE is the root mean square errors given
} as $\mathrm{gm}^{-2}$. Values in parentheses indicate the inversions using the whole AIRS satellite data set in contrast to using only one AIRS overpass on 9 August. Bold values indicate the three eruption times for which each meteorological data set yielded the highest correlations and lowest RMSE. Abbreviations are as follows: AIRS, Atmospheric InfraRed Sounder; ECMWF, European Centre for Medium-Range Weather Forecasts; GFS, National Centers for Environmental Prediction Global Forecast; GOME-2, Global Ozone Monitoring Experiment-2; and OMI, Ozone Monitoring Instrument.

tend to be lower when using data from all three instruments at the same time. This can be explained by the biases in the satellite data, which deteriorate correlations. Nevertheless, we expect that inverted profiles are most reliable when all data are used. Figure 5 shows the three best estimates of the inversion profiles based on all satellite data for each eruption time, 2201 UTC (red line) using ECMWF data, and 0150 and 0435 UTC using GFS data (green line and blue line, respectively). While the shape and magnitude of the strong stratospheric peak $(\sim 12 \mathrm{~km})$ is very similar for all inversion experiments, the altitude of the tropospheric peak depends on

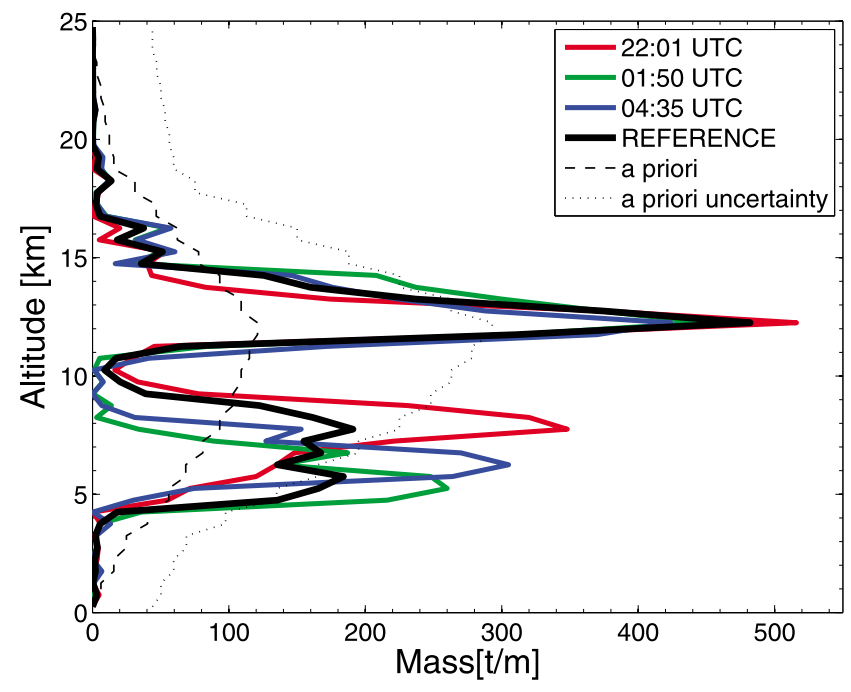

Figure 5. Inversion results when using combined satellite data from all three platforms (GOME-2, OMI, and AIRS) for three different assumed eruption times: 2201 UTC on 7 August 2008 (red line) and 0150 UTC (green line) and 0435 UTC (blue line) on 8 August 2008. The reference profile (thick black line) is the average of the 2201 UTC and the 0150 UTC profiles. The ECMWF meteorological data set was used for driving the FLEXPART simulations used for the 2201 UTC inversion, while for 0150 and 0435 UTC the GFS data were used. the assumed eruption time. Overall, however, the emission profile is quite robust and does not depend strongly on the assumed eruption time. It also does not depend strongly on the choice of the meteorological input data used for driving FLEXPART. This can be related to the steady wind fields at Kasatochi for both ECMWF and GFS over the interval that the eruptions occurred. The total mass of $\mathrm{SO}_{2}$ is $1.7 \pm 0.08 \mathrm{Tg}$ for all profiles, with $1.0 \pm 0.11 \mathrm{Tg}$ stratospheric injection (higher than $10 \mathrm{~km}$ ) and emission up to a maximum altitude of $\sim 20 \mathrm{~km}$.

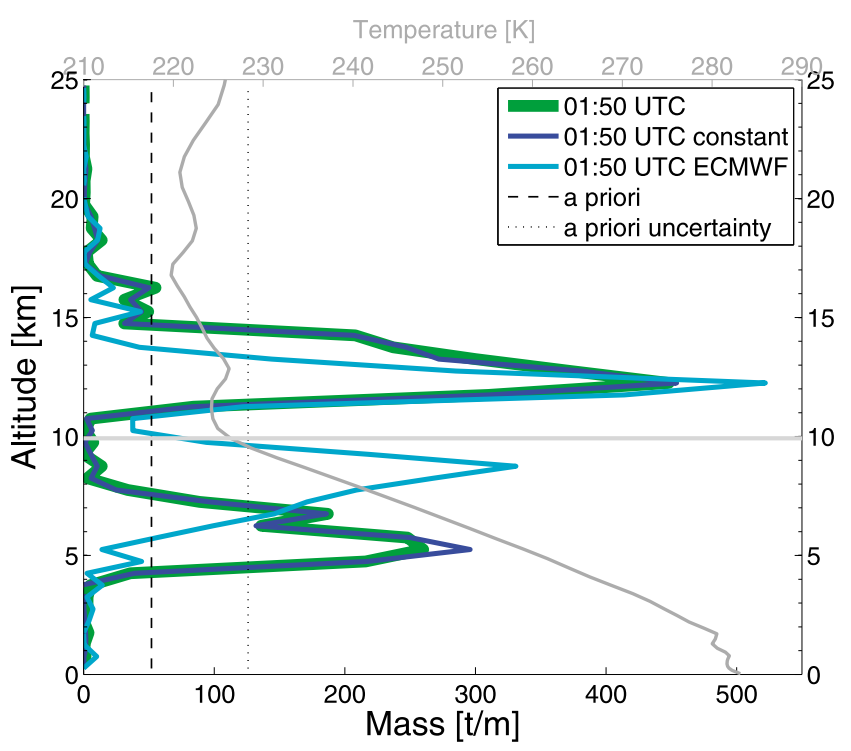

Figure 6. Sensitivity experiments with the inversion algorithm. The profile 0150 UTC (green line) is the same result as shown in Figure 5. The profile 0150 UTC constant (blue line) uses constant a priori emissions (flat a priori profile). The profile 0150 UTC ECMWF (turquoise line) is the inversion result when using ECMWF meteorological data for driving the FLEXPART simulations used for the inversion instead of using GFS data. The dark gray line is the ECMWF temperature profile for $\left(52^{\circ} \mathrm{N}, 176^{\circ} \mathrm{W}\right)$ at 0000 UTC on 8 August. The tropopause diagnosed from ECMWF data is located at $10 \mathrm{~km}$ (light gray line). 
a)

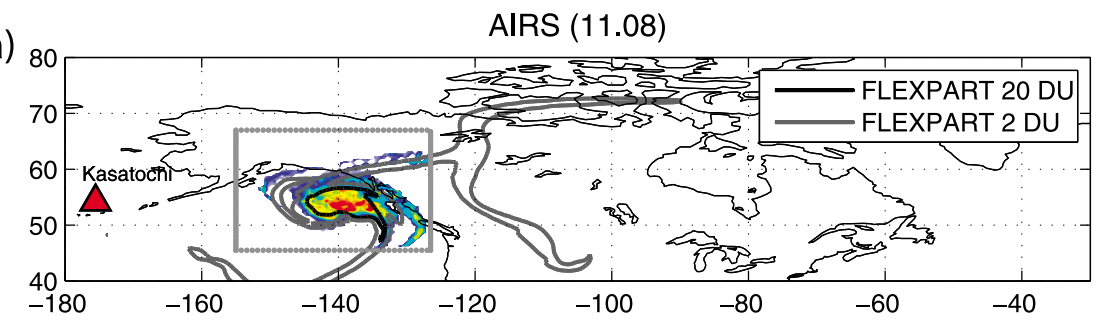

b)

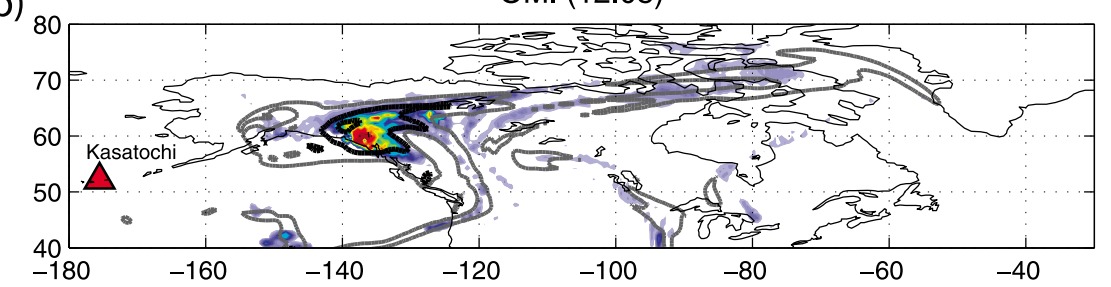

c)

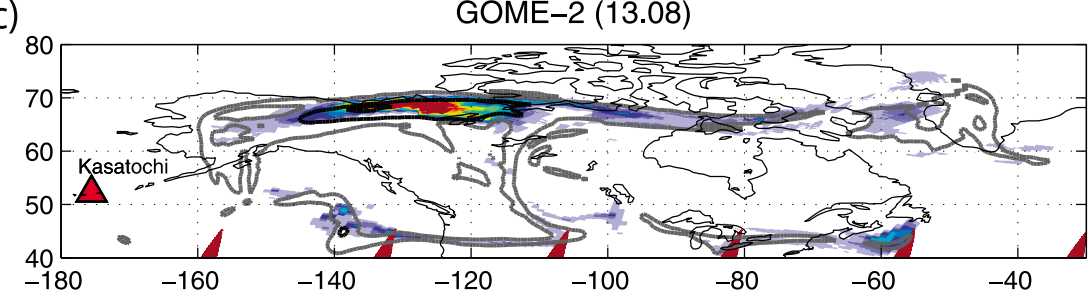

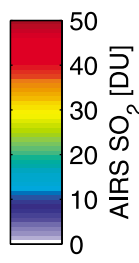
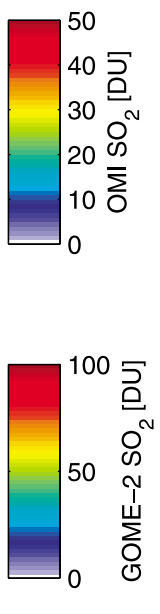

Figure 7. Comparison of $\mathrm{SO}_{2}$ columns measured by satellite and simulated by FLEXPART using the emission profile from the reference inversion. Satellite data (a) AIRS for 11 August at 2205 UTC, (b) OMI for 12 August, and (c) GOME-2 for 13 August 2008 are shown by the color shadings, and the FLEXPART results, driven with ECMWF data, are shown as isolines for 2 DU (thick gray line) and 20 DU (thick black line). For AIRS, the satellite's approximate swath width boundaries are shown by the gray square. The Kasatochi Volcano is marked by a red triangle.

[53] In principle, we could set up the inversion such that the emissions are not only determined as a function of altitude but also of time. However, since the three eruptions occurred during such a short time interval and the inversion results are very similar, the emissions of the three eruptions cannot be clearly separated by the inversion. Therefore, we chose the two profiles with highest correlation, the "ALL 2201 ECMWF" and "ALL 0150 GFS," to define the average of these two profiles as the so-called "reference" profile (thick black line in Figure 5). This profile was subsequently used to perform a long-range transport simulation by assigning the $\mathrm{SO}_{2}$ emissions to a time window from the first to the second eruption time.

[54] Maerker et al. [2008] used a trajectory matching technique based on FLEXPART simulations and GOME-2 satellite $\mathrm{SO}_{2}$ observations, to estimate the $\mathrm{SO}_{2}$ height emission profile of the Kasatochi eruption and found emission peaks at 8-9 $\mathrm{km}$ and $12-14 \mathrm{~km}$. Also, Theys et al. [2009] found that the injection altitude of emitted bromine monoxide $(\mathrm{BrO})$ by Kasatochi, which may be collocated with $\mathrm{SO}_{2}$, was located between 8 and $12 \mathrm{~km}$ altitude. Our inversion results agree with these height estimates.

[55] In Figure 6, results from some sensitivity experiments are shown. All profiles are for an assumed 0150 UTC eruption time. The 0150 UTC profile (thick green line in Figure 6) is the same as the result in Figure 5, repeated for comparison. The 0150 UTC constant profile (blue line in Figure 6) shows the inversion profile using a constant a priori rather than an a priori based on IASI estimates. The similarity between these two profiles demonstrates that with a sufficiently large satellite data set the inversion results are robust to changes in the a priori, as stated also by Eckhardt et al. [2008]. The 0150 UTC ECMWF profile (turquoise line in Figure 6) is the inversion result when using ECMWF instead of GFS meteorological data for driving the FLEXPART simulations used for the inversion, which result in somewhat lower correlation $(0.60$ versus 0.62$)$ for this eruption time. The lower-altitude emission peak is located higher than for the GFS results, which is generally the case for the ECMWF results for all eruption times.

[56] Figure 6 also shows the ECMWF temperature profile (dark gray line in Figure 6) for the nearest grid point $\left(52^{\circ} \mathrm{N}\right.$, $176^{\circ} \mathrm{W}$ ) to the volcano, as well as the ECMWF tropopause height (light gray line in Figure 6) located at $10 \mathrm{~km}$. There are no emissions at the tropopause height. The high stratospheric emission peak is collocated with a layer of enhanced stability in the atmospheric temperature profile, which is associated with detrainment of air from the rising eruption column. In the troposphere, except for the lowest $2 \mathrm{~km}$, there is no layer with particularly large stability, so there does not seem to be a height where detrainment is most likely to occur.

\subsection{Simulation and Validation of $\mathrm{SO}_{2}$ Transport}

[57] The transport of the volcanic $\mathrm{SO}_{2}$ cloud was simulated with FLEXPART using emissions according to the 

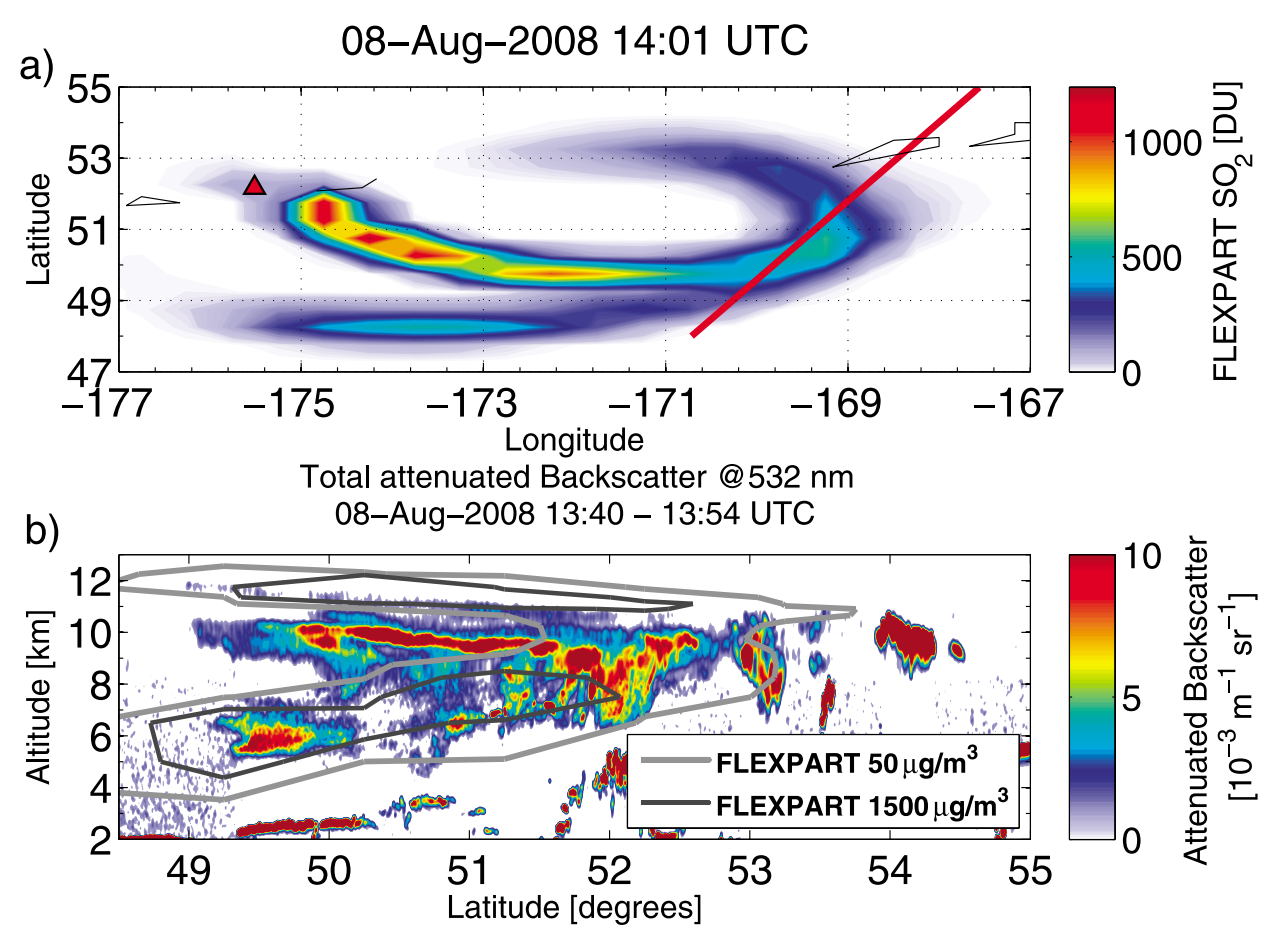

Figure 8. Comparison of CALIPSO attenuated backscatter at $532 \mathrm{~nm}$ with $\mathrm{SO}_{2}$ concentrations simulated by FLEXPART on 8 August. (a) Total columns of $\mathrm{SO}_{2}$ simulated by FLEXPART. The red line indicates the location of the CALIPSO nadir track. (b) CALIPSO data shown by color shadings and FLEXPART results plotted as isolines for $50 \mu \mathrm{g} \mathrm{m}^{-3}$ (thick gray line) and $1500 \mu \mathrm{g} \mathrm{m}^{-3}$ (thick black line).

reference inversion profile shown in Figure 5. Particles were released continuously from 2201 UTC on 7 August until 0150 UTC on 8 August because the results presented in section 6.2 did not allow unambiguous determination of a single most appropriate time. While GOES imagery suggest the largest burst of volcanic ash at the third eruption time (0450 UTC), Waythomas et al. [2008] indicate an inconsistency between the timing of the ash and $\mathrm{SO}_{2}$ emissions. The first two events produced relatively gas rich but ash poor eruption clouds whereas the third event produced an ash- and gas-rich plume. It is therefore likely that a large part of the emitted $\mathrm{SO}_{2}$ was released at the two first eruption events. The long-range transport simulation was compared with independent satellite data; that is, measurements which were not used for the inversion. Comparisons with lidar measurements were also performed to evaluate the height of the simulated $\mathrm{SO}_{2}$.

[58] The long-range transport simulations were performed using both ECMWF data and GFS initial meteorological data. Comparisons and validations showed better agreement when using ECMWF data for the simulation, which is probably due to the higher vertical resolution of the ECMWF data (91 vertical levels compared to 26 levels for GFS) or differences in the assimilation of meteorological data. Thus, only the results using ECMWF data are shown in this section and the results using GFS data are only described where they clearly differ from the ECMWF results.

\subsubsection{Comparison With Independent Satellite Data}

[59] Figure 7 shows the FLEXPART simulation using the reference emission profile from Figure 5 compared with independent satellite data from AIRS on 11 August, OMI on 12 August and GOME-2 on 13 August. The FLEXPART results are weighted with the respective averaging kernel from Figure 2.

[60] On 10 August, 3 days after the eruption, the $\mathrm{SO}_{2}$ cloud hit the coast of Alaska and was split into a filamentary two-tailed cloud. One filament stretched across northern Canada toward Greenland and the other spread toward the southern Great Lakes. It was the efficient transport by the jet stream $(\sim 12 \mathrm{~km})$ that caused the fast movement of the cloud across North America. The AIRS satellite overpass on 11 August at 2205 UTC captured one part of the $\mathrm{SO}_{2}$ cloud, with the swath width boundaries of the overpass indicated with the gray square (Figure 7a). For areas covered by the AIRS observations there is very good agreement between the model simulation and the measurements. The shape of the cloud is especially simulated very well with a distinct sharp bend at the cloud's southern end, and filaments stretching northward and southward.

[61] On 12 August, the main part of the $\mathrm{SO}_{2}$ cloud drifted northeastward and was located over western Canada (Figure 7b) while the northernmost filament was transported by the jet stream toward Greenland. The OMI satellite observations are composites of data collected for various moments during the day, while the FLEXPART results show the dispersed $\mathrm{SO}_{2}$ at 2101-2201 UTC. Despite the time differences there is good agreement between measurements and FLEXPART simulation. The shape of the main part of the cloud as well as the southern filament over the Pacific Ocean is captured very well, while there are some observations near Hudson Bay in Canada that are 


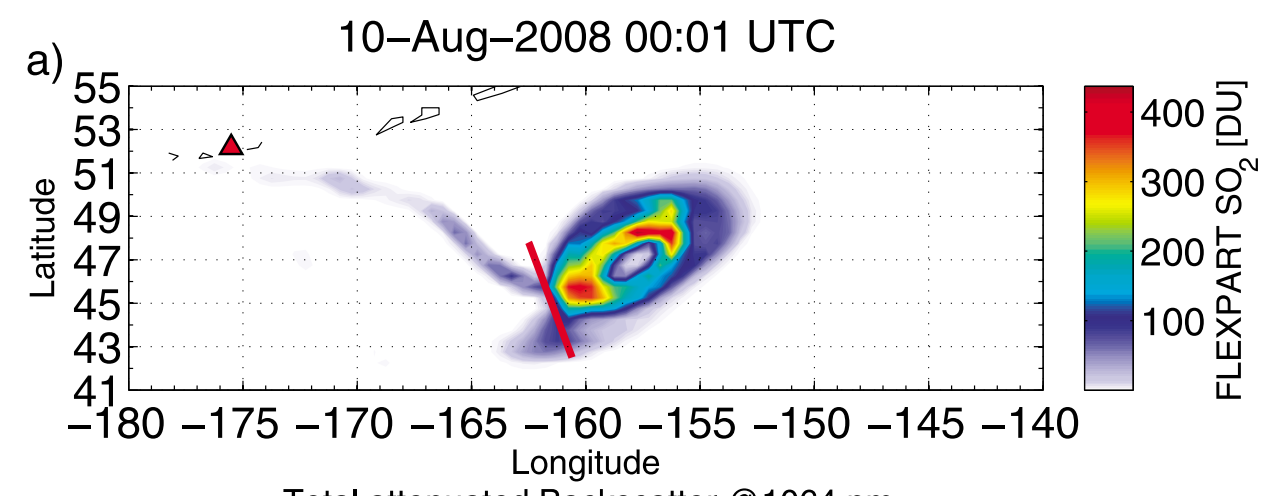

b) 09-Aug-2008 23:51 UTC - 10-Aug-2008 00:05 UTC

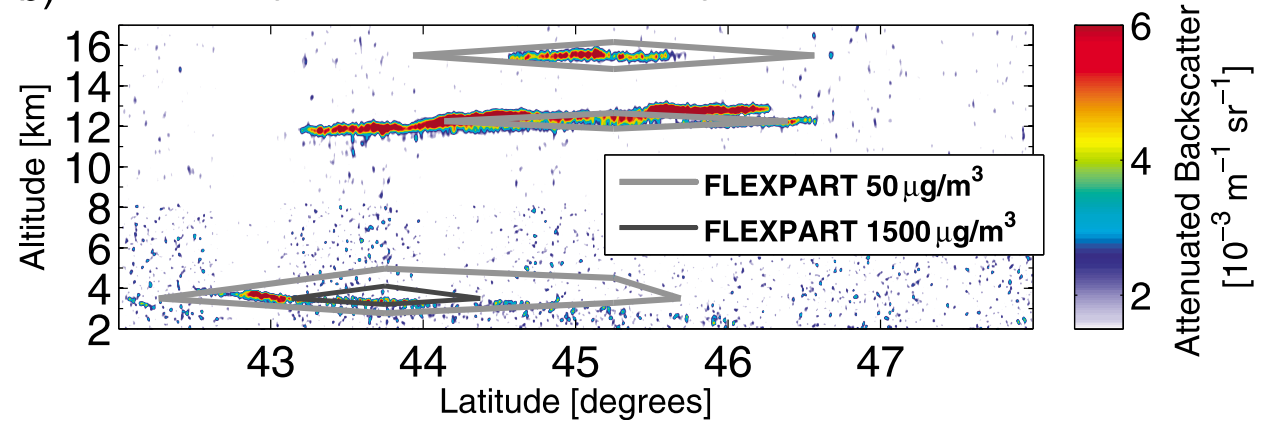

Figure 9. Comparison of CALIPSO attenuated backscatter at $1064 \mathrm{~nm}$ with $\mathrm{SO}_{2}$ concentrations simulated by FLEXPART on 10 August 2008. (a) Total columns of $\mathrm{SO}_{2}$ simulated by FLEXPART. The red line indicates the location of the CALIPSO nadir track. (b) CALIPSO data shown by the color shadings and the FLEXPART results plotted as isolines for $50 \mu \mathrm{g} \mathrm{m}^{-3}$ (thick gray line) and $1500 \mu \mathrm{g} \mathrm{m}^{-3}$ (thick black line).

not simulated as well by FLEXPART. However, the model simulation using GFS data shows a better comparison for the areas around Hudson Bay (not shown), which confirms that this is part of the volcanic cloud.

[62] On 13 August, 6 days after the eruption, the $\mathrm{SO}_{2}$ filament cloud reached the Atlantic Ocean, while the main part was found over northern Canada (Figure 7c). The GOME-2 observations, shown as composites of overpasses during the day and the FLEXPART results for 1601-1701 UTC are in good agreement. The main features of the cloud are captured very well by the model. Especially the position of maximum signal over Canada correlates very well with the measurements. The two filaments of the cloud stretching over U.S and Canada, and also the filament remaining over the Pacific Ocean have distinct limits that the model recaptures. However, it seems that the modeled cloud over Greenland and the westernmost part of the cloud over Alaska are covering larger areas than the observed cloud, so that an overestimation of about $2 \mathrm{DU}$ is visible in these areas.

[63] Some of the minor discrepancies between the model and satellite data may be due to that $\mathrm{SO}_{2}$ loss is only estimated by FLEXPART, as described in section 3. The e-folding time for the loss of $\mathrm{SO}_{2}$ in the model simulation is about 1 day in the boundary layer, about 20 days for the upper troposphere and 50 days for the stratosphere, which is in agreement with loss rates found in literature [e.g., Bluth et al., 1997]. Thus, the loss of tropospheric $\mathrm{SO}_{2}$ in the model is to some extent important for validation about a week after the eruption, whereas stratospheric loss is very slow and nearly negligible.

\subsubsection{Comparison With Space-Based Lidar Measurements}

[64] CALIPSO profiles of total attenuated backscatter at $532 \mathrm{~nm}$ and $1064 \mathrm{~nm}$ (level 1B data) are compared with $\mathrm{SO}_{2}$ concentrations simulated by FLEXPART to evaluate the altitude of the simulated $\mathrm{SO}_{2}$ cloud. The comparison is qualitative as we compare two different quantities: concentration of $\mathrm{SO}_{2}$ with backscatter from particulate matter (aerosols and clouds).

[65] The comparisons between the model simulation and CALIPSO data occurred where the volcanic cloud was observed by other satellite instruments (see Figures 1 and 3) and where the scattering particles can be confidently identified as of volcanic origin. In addition, at this latitude some of the altitudes used for comparison (above 10-12 km) are seldom reached by other type of aerosols or liquid water clouds, but there may be ice clouds.

[66] Figure 8 shows the $\mathrm{SO}_{2}$ cloud simulated by FLEXPART on 8 August $(\sim 15 \mathrm{~h}$ after the eruption) with the CALIPSO nadir track overlaid (Figure $8 \mathrm{a}$ ). The simulated transport patterns agree very well with the satellite observations in Figure 1, which were used for the inversion. Layers of enhanced attenuated backscatter are found between 5 and $11 \mathrm{~km}$ (Figure 8b), while the cloud simulated by FLEXPART has two $\mathrm{SO}_{2}$ layers centered at $6-8$ and 11-12 km, coinciding with the two emission maxima of 

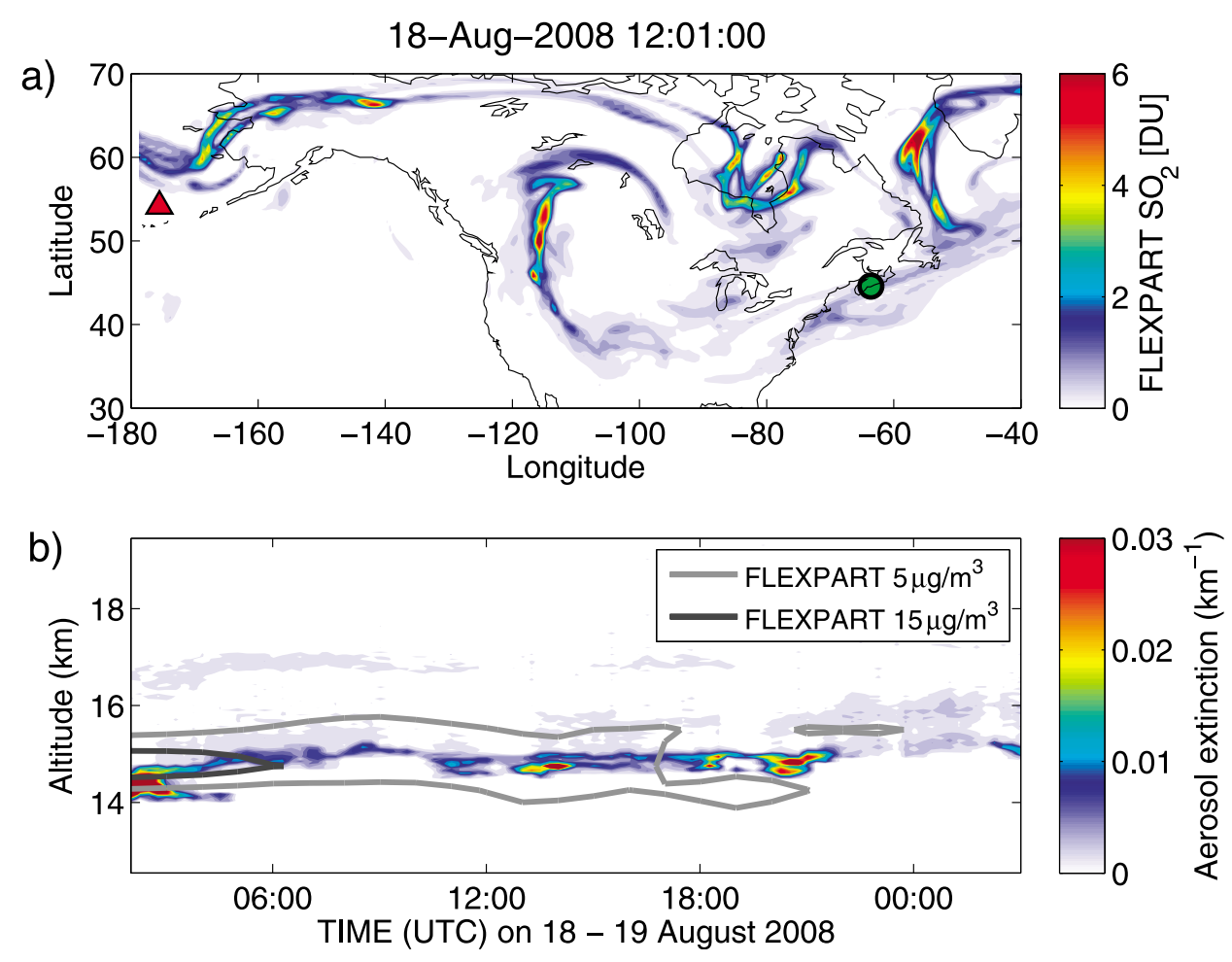

Figure 10. Comparison of aerosol extinction coefficients measured at Nova Scotia on 18-19 August and $\mathrm{SO}_{2}$ concentrations simulated by FLEXPART. (a) Total columns of $\mathrm{SO}_{2}$ simulated by FLEXPART from 18 August. The lidar at Nova Scotia is marked with a green dot. (b) Lidar measurements shown by the color shadings and the FLEXPART results plotted as isolines for $5 \mu \mathrm{g} \mathrm{m}^{-3}$ (thick gray line) and $15 \mu \mathrm{g} \mathrm{m}^{-3}$ (thick black line).

the reference profile (Figure 5). Generally the simulated $\mathrm{SO}_{2}$ cloud is broader than the CALIPSO features.

[67] The lowest part of the simulated $\mathrm{SO}_{2}$ cloud $(5-9 \mathrm{~km})$ coincides very well with the CALIPSO measurements, especially the way the altitude of the lowest part of the cloud increases with latitude. However, the CALIPSO Level 2 data product classifies this area as meteorological clouds with some minor aerosol near $5 \mathrm{~km}$. The conversion from $\mathrm{SO}_{2}$ to sulphate is on the order of a few days in the lower troposphere, which may indicate that, at this early stage after the eruption, CALIPSO sees volcanic ash, or possibly a mixture of ash, sulphate and cloud. Also the attenuated color ratio $(1064 / 532 \mathrm{~nm})$ is high $(1.4-1.6)$ for this low part of the observed layers, indicating large particles. Prata et al. [2010] show that volcanic ash and $\mathrm{SO}_{2}$ traveled together for at least 3 days after the eruption, thus the comparison of the simulated $\mathrm{SO}_{2}$ and the CALIPSO features seems reasonable.

[68] For the tropopause region $(\sim 10 \mathrm{~km})$, layers with enhanced backscatter are found mainly around $10 \mathrm{~km}$, while the simulated cloud is located at 11-12 km. CALIPSO's scene classification imply mostly meteorological clouds, the minor $11-12 \mathrm{~km}$ feature between $49^{\circ} \mathrm{N}$ and $52^{\circ} \mathrm{N}$ is classified as "stratospheric feature." This feature shows a stronger signal at $532 \mathrm{~nm}$, indicating smaller particles, thus may be small sulphate particles starting to form from the $\mathrm{SO}_{2}$. The dislocation between the observed $10 \mathrm{~km}$ layer and the simulated $12 \mathrm{~km}$ layer may be explained by the very slow conversion rate from $\mathrm{SO}_{2}$ to sulfate in the stratosphere, thus sulfate particles have not yet started to form at $12 \mathrm{~km}$. Or, if the observed features at $10 \mathrm{~km}$ are volcanic ash particles, they may have subsided owing to gravitational settling. The depolarization ratio for the observations is $0.2-0.4$. Interestingly, the cirrus cloud (strong backscatter, higher depolarization of $0.4-0.5$ ) at $\sim 10 \mathrm{~km}$ and $54^{\circ} \mathrm{N}$ is not part of the simulated volcanic cloud.

[69] Figure 9 shows a similar comparison of the $\mathrm{SO}_{2}$ cloud transport simulated by FLEXPART and the CALIPSO measurements from 10 August ( $48 \mathrm{~h}$ after the eruption). Visually the transport patterns agree with the satellite observations in Figure 3, also used for the inversion. The CALIPSO track (Figure 9a) cuts through the $\mathrm{SO}_{2}$ cloud at around $162{ }^{\circ} \mathrm{W}$. The enhanced backscatter at $1064 \mathrm{~nm}$ is shown as some of the observed features were more clearly visible at this wavelength rather than at $532 \mathrm{~nm}$. Three thin veils of enhanced backscatter are observed between 43 and $47^{\circ} \mathrm{N}$ at $\sim 3 \mathrm{~km}, \sim 12 \mathrm{~km}$ and $\sim 15 \mathrm{~km}$ altitude (Figure $9 \mathrm{~b}$ ). The FLEXPART model results show similar layers centered at the same altitudes, but the highest layer is covering a broader vertical range, the middle layer is narrower and the lowest layer is broader and extending further north. For the lowest layer it is the bottom part of the maximum that corresponds to the CALIPSO feature. The two highest CALIPSO layers are characterized as stratospheric features, while the lowest layer is a mixture of aerosol and cloud. The stratospheric layer has depolarization ratio around $0.1-0.2$ and color ratio less than 1 , indicating a potential mixture of sulphate aerosols and other volcanic debris. Both the 

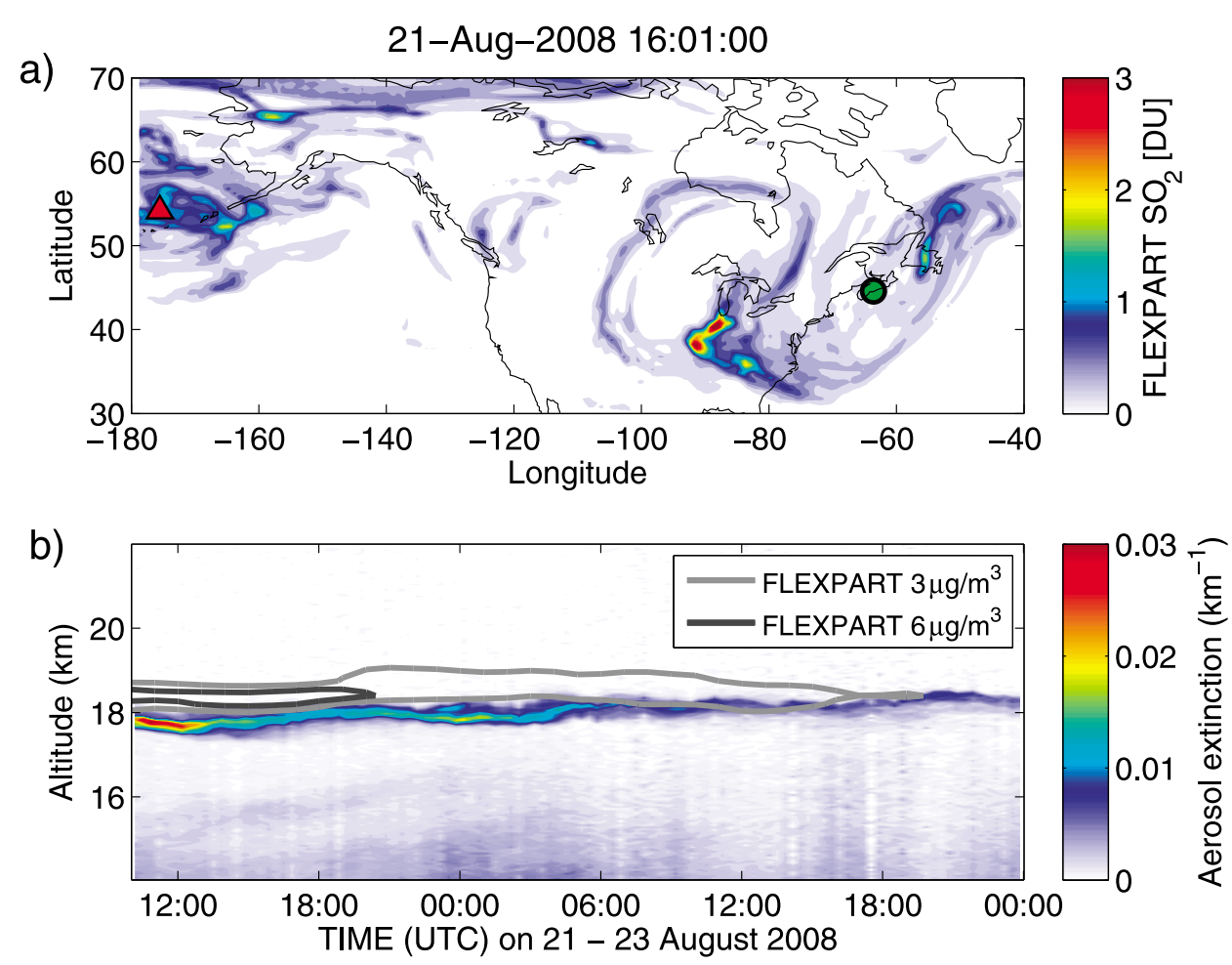

Figure 11. Comparison of aerosol extinction coefficients measured at Nova Scotia on 21-23 August and $\mathrm{SO}_{2}$ concentrations simulated by FLEXPART. (a) Total columns of $\mathrm{SO}_{2}$ simulated by FLEXPART from 21 August. The lidar at Nova Scotia is marked with a green dot. (b) Lidar measurements shown by the color shadings and the FLEXPART results plotted as isolines for $3 \mu \mathrm{g} \mathrm{m}^{-3}$ (thick gray line) and $6 \mu \mathrm{g} \mathrm{m}^{-3}$ (thick black line).

depolarization ratio and the color ratio are highest for the layer in the lower troposphere, indicating larger particles (volcanic ash). The larger extent of the $\mathrm{SO}_{2}$ layer compared to the area with enhanced backscatter can be due to wash out of the sulfate particles and ash at this low altitude. Overall, the approximate $\mathrm{SO}_{2}$ cloud position and especially the three-layer structure and the three layers' mean altitudes are well captured.

\subsubsection{Comparison With Ground-Based Lidar Measurements}

[70] To further validate the height of the simulated $\mathrm{SO}_{2}$ cloud, we used ground-based lidar measurements at two different locations. These lidar observations were taken from 8 to 25 days after the eruption, at locations over $100^{\circ}$ east of the volcano. Since the ash from the eruption was likely deposited after a few days, the observations that can be related to the eruption are of sulphate aerosols.

[71] The Kasatochi cloud was observed by the Dalhousie Raman lidar at Halifax, Nova Scotia $\left(44.6^{\circ} \mathrm{N}, 63.6^{\circ} \mathrm{W}\right)$ on the eastern coast of Canada. The measurements of the $\mathrm{SO}_{2}$ cloud were available over a 4 month period from 15 August to 4 December 2008, and have been examined in more detail by Bitar et al. [2010].

[72] Figure 10 shows the FLEXPART $\mathrm{SO}_{2}$ cloud on 18 August and lidar measurements from 18 to 19 August 2008 with corresponding FLEXPART isolines overlaid. The lidar position is marked with a green dot. The $\mathrm{SO}_{2}$ cloud is found mostly over the northern United States, Canada, over western Alaska and over Greenland, and there are also debris over Nova Scotia (Figure 10a). The aerosol extinction coefficients indicate an aerosol layer at $\sim 14-15 \mathrm{~km}$ altitude, which corresponds very well to the $\mathrm{SO}_{2}$ layer height simulated by FLEXPART, but the measured aerosol plume is narrower in its vertical extent than the simulated $\mathrm{SO}_{2}$ cloud (Figure 10b). Also the maximum $\mathrm{SO}_{2}$ concentration at around 0300 UTC on 18 August is located slightly higher than the maximum aerosol concentration.

[73] Figure 11 shows simulated $\mathrm{SO}_{2}$ cloud and lidar measurements from 21 to 23 August 2008. The simulated $\mathrm{SO}_{2}$ cloud is still visible over Nova Scotia (Figure 11a), and an observed layer at $\sim 18 \mathrm{~km}$ fits very well with the simulated cloud to within $\pm 0.5 \mathrm{~km}$ (Figure $11 \mathrm{~b}$ ). This coincides with the minor emission peak at $\sim 18 \mathrm{~km}$ of our reference emission height profile (Figure 5), and thus the lidar measurements provide validation that the emissions from Kasatochi reached at least $18-20 \mathrm{~km}$ altitude.

[74] Observations of the Kasatochi cloud were also performed using a ground based lidar at AWIPEV station, in Ny Ålesund $\left(78.9^{\circ} \mathrm{N}, 11.9^{\circ} \mathrm{E}\right)$ on Svalbard. The lidar measurements of the Kasatochi cloud were taken from 15 August to 24 September 2008. Several layers were observed at about $10-12 \mathrm{~km}$ and $15-17 \mathrm{~km}$ altitude [Hoffmann et al., 2010]. Figure 12 shows the simulated $\mathrm{SO}_{2}$ cloud and lidar measurements from 15 August with FLEXPART isolines overlaid. The $\mathrm{SO}_{2}$ cloud has stretched out from Alaska all the way to Europe. From the model simulation (Figure 12a) a thin filament of the cloud has reached the lidar on Svalbard (green dot in Figure 12a), and small amounts 
15-Aug-2008 11:01:00
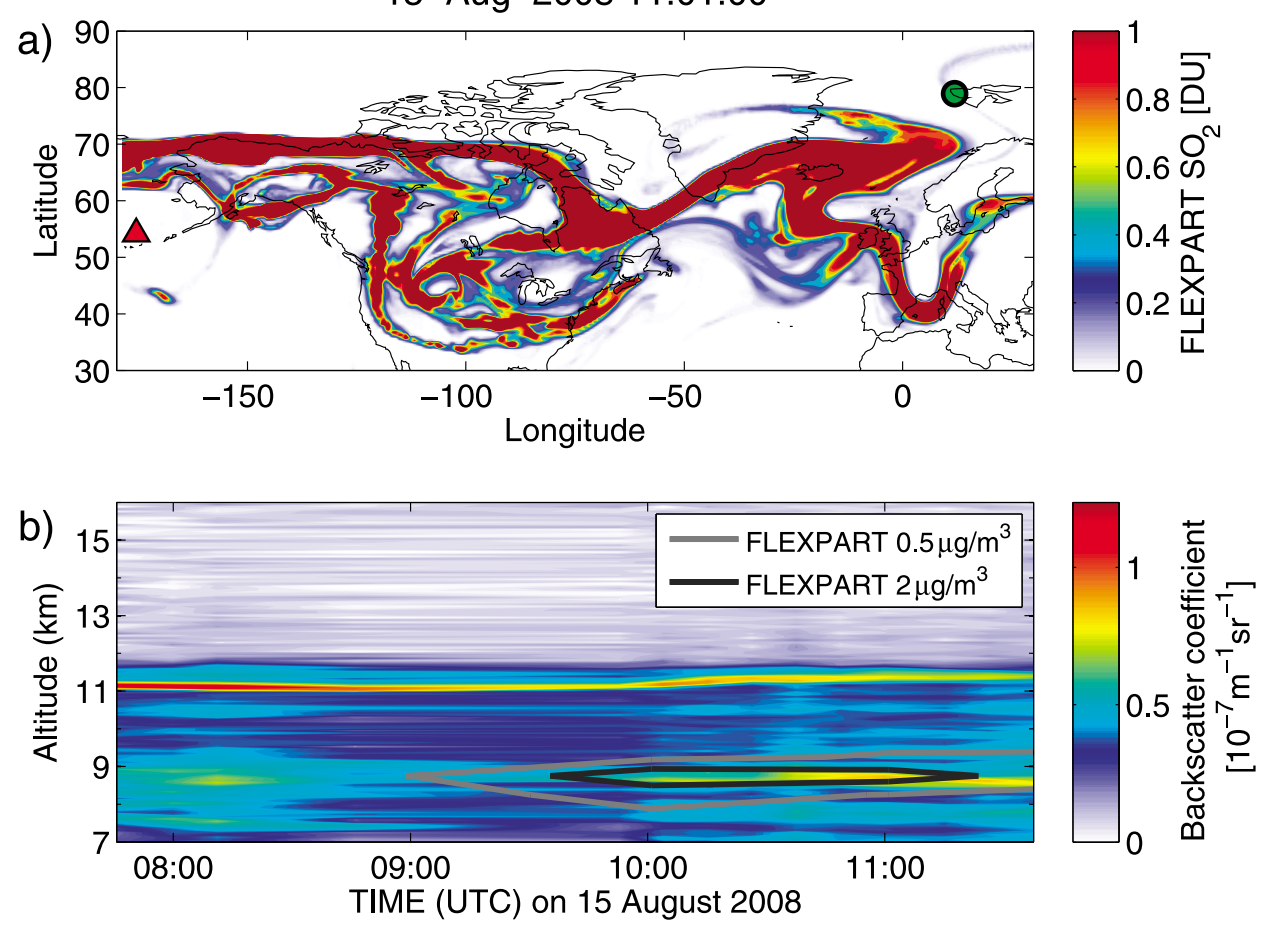

Figure 12. Comparison of aerosol backscatter coefficient measured at Ny Ålesund on 15 August and $\mathrm{SO}_{2}$ concentrations simulated by FLEXPART. (a) Total columns of $\mathrm{SO}_{2}$ simulated by FLEXPART from 15 August. The lidar at Ny Ålesund is marked with a green dot. (b) Lidar measurements shown by the color shadings and the FLEXPART results plotted as isolines for $0.5 \mu \mathrm{g} \mathrm{m}^{-3}$ (thick gray line) and $2 \mu \mathrm{g} \mathrm{m}^{-3}$ (thick black line).

$\left(0.5-2.0 \mu \mathrm{g} \mathrm{m}^{-3}\right)$ of $\mathrm{SO}_{2}$ are found at an altitude of $8-10 \mathrm{~km}$ above Ny Allesund (Figure 12b). This is in agreement with high aerosol backscatter coefficients. The lidar observations also show an aerosol layer at $\sim 11 \mathrm{~km}$ altitude which is not found in the model simulation. Only for the observations after 25 August, is this layer present in the model simulation, as shown in Figure 13 for 1 September. Here, there is also a very weak aerosol layer observed at $17 \mathrm{~km}$ (Figure 13b) which is also visible in the model simulation. The lidar measurements from 1 September have been examined in detail by Hoffmann et al. [2010]. Generally, for all lidarmodel comparisons, the altitude of the simulated cloud agrees very well with the different lidar observations, but the modeled cloud is generally broader than the measured aerosol plume in its vertical extent.

\section{Summary and Conclusions}

[75] An inversion method was used in this study to estimate the vertical profile of $\mathrm{SO}_{2}$ emissions from the eruption of Kasatochi Volcano in August 2008. This was done by using total column measurements of $\mathrm{SO}_{2}$ from satellite instruments (GOME-2, OMI and AIRS) and a Lagrangian dispersion model, FLEXPART. Conclusions from this study are summarized as follows:

[76] 1. Emission height profiles of $\mathrm{SO}_{2}$ were estimated by using $\mathrm{SO}_{2}$ column data from GOME-2, OMI and AIRS for 2 days after the eruption. Two meteorological data sets (ECMWF and GFS) and three different eruption times were tested; 2201 UTC on 7 August and 0150 and 0435 UTC on
8 August. The first two eruption times yielded the highest correlation between measurements and model results. Generally, two large emission maxima were found; one in the stratosphere $(\sim 12 \mathrm{~km})$, and one in the middle-upper troposphere $(\sim 7 \mathrm{~km})$. The largest emission peak extended up to $\sim 17 \mathrm{~km}$ which agreed with reports from AVO stating emissions up to $14.5-16.5 \mathrm{~km}$, but smaller emissions were obtained for up to $\sim 20 \mathrm{~km}$. According to the "reference" inversion (using satellite data from all three platforms), $\sim 1.7 \pm 0.08 \mathrm{Tg} \mathrm{SO} \mathrm{SO}_{2}$ were emitted to the atmosphere, of which $\sim 60 \%$ were injected above the tropopause located at $10 \mathrm{~km}$. The estimated emission height profiles showed good agreement with height emission profiles from independent studies, such as estimates based on a trajectory ensemble technique [Maerker et al., 2008], and also Theys et al. [2009].

[77] 2. The long-range dispersion of the $\mathrm{SO}_{2}$ cloud was simulated by FLEXPART using emissions according to our best-guess "reference" inversion profile. The cloud spread mainly southeastward from the volcano and took on a circular shape owing to a passing cyclone. The cloud was further transported toward the coast of Alaska where it split into two and traversed the North American continent in two filaments before reaching the Atlantic Ocean and Europe within a week after the eruption. The simulated $\mathrm{SO}_{2}$ cloud was compared to independent satellite data up to 6 days after the eruption. There was overall good agreement between the simulated cloud and the observations.

[78] 3. The height of the simulated $\mathrm{SO}_{2}$ cloud was evaluated in a qualitative manner using lidar measurements. 

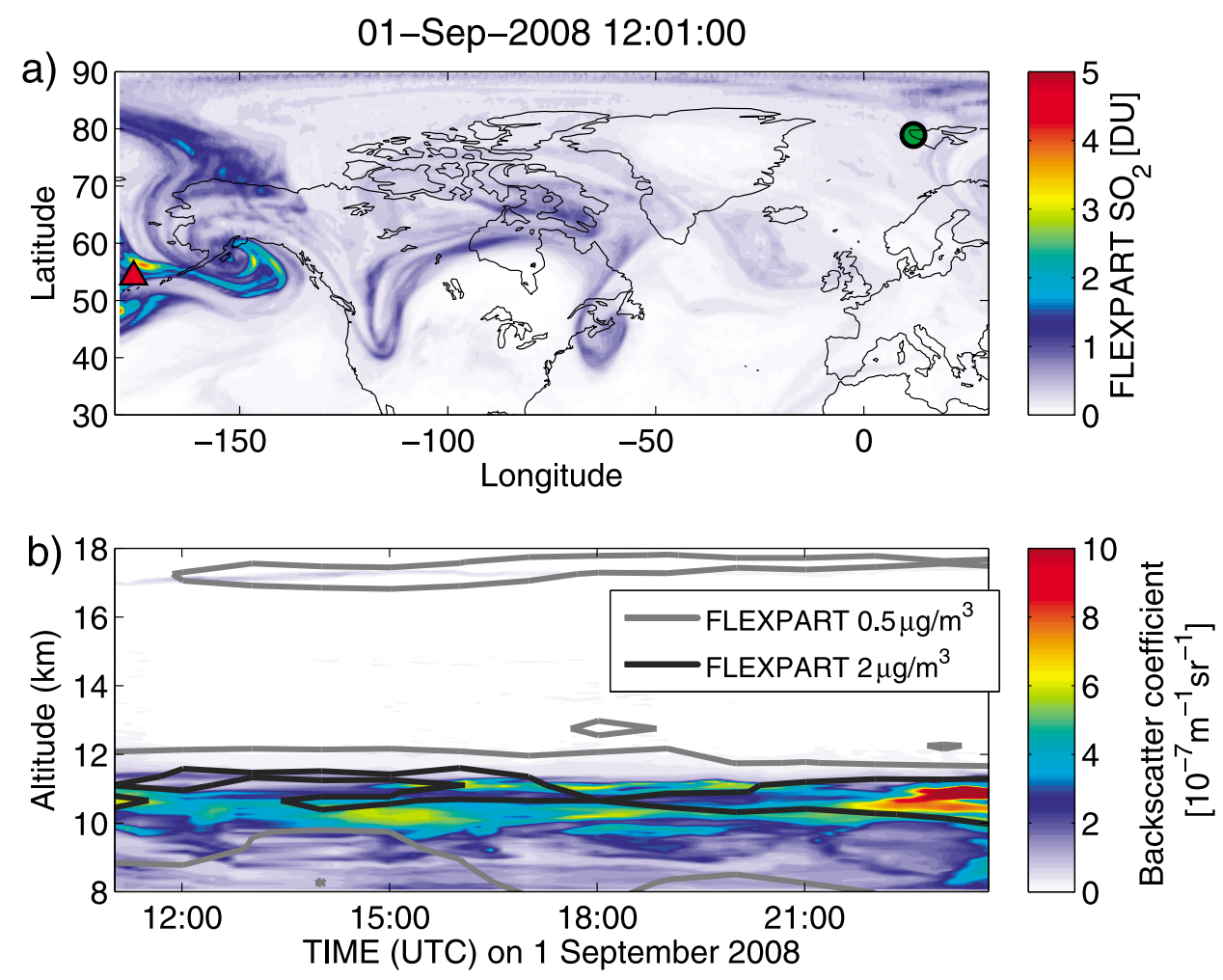

Figure 13. Comparison of aerosol backscatter coefficient measured at Ny Ålesund on 1 September and $\mathrm{SO}_{2}$ concentrations simulated by FLEXPART. (a) Total columns of $\mathrm{SO}_{2}$ simulated by FLEXPART. The lidar at Ny Ålesund is marked with a green dot. (b) Lidar measurements shown by the color shadings and the FLEXPART results plotted as isolines for $0.5 \mu \mathrm{g} \mathrm{m}^{-3}$ (thick gray line) and $2 \mu \mathrm{g} \mathrm{m}^{-3}$ (thick black line).

Compared to CALIPSO measurements on 8 and 9 August, one and 2 days after the eruption, the height of the simulated cloud agrees very well. In particular, three separate layers were identified at altitudes within $\sim 1 \mathrm{~km}$ of the altitudes of the observed layers. Compared to observations from Nova Scotia 10-15 days after the eruption the height of the modeled cloud agreed with the observations to within $\sim 1 \mathrm{~km}$, and the comparison also demonstrated that $\mathrm{SO}_{2}$ was injected to an altitude of $18-20 \mathrm{~km}$ by the volcanic eruption. The model results also agreed with observations on Svalbard 8-25 days after the eruption.

[79] Challenges and restrictions of this case study include the following:

[80] 1. The eruption of Kasatochi was characterized by three different eruption times and also subsequent continuous release, and there was no information on how much $\mathrm{SO}_{2}$ was released during each eruption. The eruptions were not clearly separable by our method, thus we made the assumption that all $\mathrm{SO}_{2}$ mass was emitted at once, using a time window between the best fitting eruption times.

[81] 2. The first satellite detection of the $\mathrm{SO}_{2}$ cloud by AIRS, GOME-2 and OMI was about 16, 23, $25 \mathrm{~h}$ after the first eruption, which makes it difficult to demonstrate a near real-time application for this case study.

[82] The inversion method presented here can provide information needed in order to calculate the actual and future position and extent of volcanic plumes. This information can be utilized in near real-time applications by, for example, the VAACs to rapidly issue warnings on volcanic ash hazards. As soon as satellite data are available for the eruption, the inversion method can be applied and the results can be ready within minutes to a few hours. Including satellite measurements of volcanic ash (rather than $\mathrm{SO}_{2}$ ) in the inversion procedure and estimating emission height profile of volcanic ash, which is more relevant for the VAACs warnings, is considered feasible and is the next step for further improvements of this method. The inversion method can also be utilized for less time-critical studies, such as facilitating the understanding of the climatic impacts of stratospheric $\mathrm{SO}_{2}$.

[83] Acknowledgments. The authors are grateful to the European Space Agency for funding this study through the SAVAA project and especially to Claus Zehner. Development of the inversion algorithm was also supported by the Norwegian Research Council as part of the SOGG-EA project. We thank I. Bey for supplying us with OH fields from GOESCHEM. We acknowledge ECMWF and the Norwegian Meteorological Institute for providing access to the ECMWF archives. CALIOP data were obtained from the NASA Langley Research Center Atmospheric Science Data Center. We are also grateful to the KNMI and NASA science and data distribution teams for use of the AIRS, GOME-2, and OMI data. We would like to thank N. Krotkov and K. Yang at GEST for useful information on the OMI retrievals for Kasatochi. Harald Sodemann at NILU is acknowledged for retrieving nested ECMWF data.

\section{References}

Bey, I., et al. (2001), Global modeling of tropospheric chemistry with assimilated meteorology: Model description and evaluation, J. Geophys. Res., 106, 23,073-23,095, doi:10.1029/2001JD000807. 
Bitar, L., T. J. Duck, N. I. Kristiansen, A. Stohl, and S. Beauchamp (2010), Lidar observations of Kasatochi Volcano aerosols in the troposphere and stratosphere, J. Geophys. Res., 115, D00L13, doi:10.1029/2009JD013650.

Bluth, G. J. S., W. I. Rose, I. E. Sprod, and A. J. Krueger (1997), Stratospheric loading of sulfur from explosive volcanic eruptions, J. Geol., 105, 671-684, doi:10.1086/515972.

Carn, S. A., A. J. Krueger, N. A. Krotkov, K. Yang, and K. Evans (2008), Tracking volcanic sulfur dioxide clouds for aviation hazard mitigation, Nat. Hazards, 51, 325-343, doi:10.1007/s11069-008-9228-4.

Casadevall, T. J. (1994), The 1989-1990 eruption of Redoubt Volcano, Alaska: Impacts on aircraft operations, J. Volcanol. Geotherm. Res., 62, 301-316, doi:10.1016/0377-0273(94)90038-8.

Chahine, M., et al. (2006), AIRS: Improving weather forecasting and providing new data on greenhouse gases, Bull. Am. Meteorol. Soc. 87, 911-926, doi:10.1175/BAMS-87-7-911.

Corradini, S., L. Merucci, A. J. Prata, and A. Piscini (2010), Volcanic ash and $\mathrm{SO}_{2}$ in the 2008 Kasatochi eruption: Retrievals comparison from different IR satellite sensors, J. Geophys. Res., doi:10.1029/ 2009JD013634, in press.

Eckhardt, S., A. J. Prata, P. Seibert, K. Stebel, and A. Stohl (2008), Estimation of the vertical profile of sulfur dioxide injection into the atmosphere by a volcanic eruption using satellite column measurements and inverse transport modeling, Atmos. Chem. Phys., 8, 3881-3897, doi:10.5194/ acp-8-3881-2008.

Emanuel, K. A., and M. Živković-Rothman (1999), Development and evaluation of a convection scheme for use in climate models, J. Atmos. Sci., 56, 1766-1782, doi:10.1175/1520-0469(1999)056<1766: DAEOAC $>2.0 . \mathrm{CO} ; 2$.

Eskes, H. J., and K. F. Boersma (2003), Averaging kernels for DOAS total-column satellite retrievals, Atmos. Chem. Phys., 3, 1285-1291, doi:10.5194/acp-3-1285-2003.

Forster, C., A. Stohl, and P. Seibert (2007), Parameterization of convective transport in a Lagrangian particle dispersion model and its evaluation, J. Appl. Meteorol. Climatol., 46, 403-422, doi:10.1175/JAM2470.1.

Halmer, M. M., and H.-U. Schmincke (2003), The impact of moderatescale explosive eruptions on stratospheric gas injections, Bull. Volcanol., 65, 433-440, doi:10.1007/s00445-002-0270-x.

Hoffmann, A., C. Ritter, M. Stock, M. Maturilli, S. Eckhardt, A. Herber, and R. Neuber (2010), Lidar measurements of the Kasatochi aerosol plume in August and September 2008 in Ny-Alesund, Spitsbergen, J. Geophys. Res., doi:10.1029/2009JD013039, in press.

Hostetler, C. A., Z. Liu, J. Reagan, M. Vaughan, M. Osborn, W. H. Hunt, K. A. Powell, and C. Trepte (2006), CALIOP Algorithm Theoretical Basis Document, Calibration and Level 1 Data Products, Rep. PC-SCI-201, NASA Langley Res. Cent., Hampton, Va. (Available at http://www-calipso. larc.nasa.gov/resources/project documentation.php.)

International Civil Aviation Organization (ICAO) (2004), Handbook on the International Airways Volcano Watch, 2nd ed., Montreal, Que. (Available at: http://www.icao.int/icaonet/dcs/9766/9766 cons en.pdf.)

Jäger, H., and T. Deshler (2002), Lidar backscatter to extinction, mass and area conversions for stratospheric aerosols based on midlatitude balloonborne size distribution measurements, Geophys. Res. Lett., 29(19), 1929 , doi:10.1029/2002GL015609.

Karagulian, F., L. Clarisse, C. Clerbaux, A. J. Prata, D. Hurtmans, and P. F. Coheur (2010), Detection of volcanic SO2, ash, and H2SO4 using the Infrared Atmospheric Sounding Interferometer (IASI), J. Geophys. Res., 115, D00L02, doi:10.1029/2009JD012786.

Klett, J. (1981), Stable analytical inversion solution for processing lidar returns, Appl. Opt., 20, 211-220, doi:10.1364/AO.20.000211.

Kristiansen, N. I. (2009), Determination of the emission height profile of volcanic emissions using inverse modeling, M.S. thesis, 82 pp., Univ. of Oslo, Oslo. (Available at http://www.duo.uio.no/publ/geofag/2009/ 90532/MasterThesis NinaIrenKristiansen.pdf.)

Krotkov, N. A., S. A. Carn, A. J. Krueger, P. K. Bhartia, and K. Yang (2006), Band residual difference algorithm for retrieval of SO2 from the AURA Ozone Monitoring Instrument (OMI), IEEE Trans. Geosci. Remote Sens., 44, 1259-1266, doi:10.1109/TGRS.2005.861932.

Maerker, K. C., P. V. Rix, and J. Van Geffen (2008), Trajectory matching and dispersion modeling of volcanic plumes utilizing space-based observations, paper presented at USEReST 2008, the 2nd Workshop on USE Remote Sensing Techniques for Monitoring Volcanoes and Seismogenic Areas, Inst. of Electr. and Electron. Eng., Naples, Italy, 11-14 Nov.

Mankin, W. G., M. T. Coffey, and A. Goldman (1992), Airborne observations of $\mathrm{SO}_{2}, \mathrm{HCl}$, and $\mathrm{O}_{3}$, in the stratospheric plume of the Pinatubo Volcano in July 1991, Geophys. Res. Lett., 19, 179-182, doi:10.1029/ 91GL02942.

McCormick, M. P., L. W. Thomason, and C. R. Trepte (1995), Atmospheric effects of the Mt. Pinatubo eruption, Nature, 373, 399-404, doi: $10.1038 / 373399 \mathrm{a} 0$.
Menke, W. (1984), Geophysical Data Analysis: Discrete Inverse Theory, 260 pp., Academic, Orlando, Fla.

Munro, R., et al. (2006), GOME-2 on MetOp, paper presented at the EUMETSAT Meteorological Satellite Conference, Eur. Org. for the Exploit. of Meteorol. Satell., Helsinki,12-16 June.

Newhall, C. G., and S. Self (1982), The volcanic explosivity index (VEI) An estimate of explosive magnitude for historical volcanism, J. Geophys. Res., 87, 1231-1238, doi:10.1029/JC087iC02p01231.

Oberhuber, J. M., M. Herzog, H.-F. Graf, and K. Schwanke (1998), Volcanic plume simulation on large scales, J. Volcanol. Geotherm. Res., 87 29-53, doi:10.1016/S0377-0273(98)00099-7.

Prata, A. J., and C. Bernardo (2007), Retrieval of volcanic $\mathrm{SO}_{2}$ column abundance from Atmospheric Infrared Sounder data, J. Geophys. Res. 112, D20204, doi:10.1029/2006JD007955.

Prata, A. J., S. A. Carn, A. Stohl, and J. Kerkmann (2007), Long range transport and fate of a stratospheric volcanic cloud from Soufrière Hills Volcano, Montserrat, Atmos. Chem. Phys., 7, 5093-5103, doi:10.5194/ acp-7-5093-2007.

Prata, A. J., G. Gangale, L. Clarisse, and F. Karagulian (2010), Ash and sulphur dioxide in the 2008 eruptions of Okmok and Kasatochi: Insights from high spectral resolution satellite measurements, J. Geophys. Res., doi:10.1029/2009JD013556, in press.

Richter, A. (2009), GOME-2 volcanic $\mathrm{SO}_{2}$ algorithm theoretical basis document, Support to Aviation for Volcanic Ash Avoidance, Norw. Inst. for Air Res., Kjeller, Norway. (Available at http://savaa.nilu.no/ PublicArchive/tabid/3207/Default.aspx.)

Richter, A., F. Wittrock, and J. P. Burrows (2006), $\mathrm{SO}_{2}$ measurements with SCIAMACHY, paper presented at the 1st Conference on Atmospheric Science, Eur. Space Ag., Frascati, Italy.

Richter, A., F. Wittrock, A. Schönhardt, and J. P. Burrows (2009), Quantifying volcanic $\mathrm{SO}_{2}$ emissions using GOME-2 measurements, paper presented at European Geosciences Union General Assembly, Vienna.

Rix, M., P. Valks, N. Hao, T. Erbertseder, and J. van Geffen (2008), Monitoring of volcanic SO2 emissions using the GOME-2 satellite instrument, paper presented at USEReST 2008, the 2nd Workshop on USE Remote Sensing Techniques for Monitoring Volcanoes and Seismogenic Areas, Inst. of Electr. and Electron. Eng., Naples, Italy, 11-14 Nov.

Rodgers, C. D. (2000), Inverse Methods for Atmospheric Soundings: Theory and Practice, 238 pp., World Sci., Singapore.

Seibert, P. (2000), Inverse modeling of sulfur emissions in Europe based on trajectories, in Inverse Methods in Global Biogeochemical Cycles, Geophys. Monogr. Ser., vol. 114, edited by P. Kasibhatla et al., pp. 147-154, AGU, Washington, D. C.

Solomon, S., R. W. Portmann, R. R. Garcia, W. Randel, F. Wu, R. Nagatani, J. Gleason, L. Thomason, L. R. Poole, and M. P. McCormick (1998), Ozone depletion at midlatitudes: Coupling of volcanic aerosols and temperature variability to anthropogenic chlorine, Geophys. Res. Lett., 25, 1871-1874, doi:10.1029/98GL01293.

Stohl, A., and D. J. Thompson (1999), A density correction for Lagrangian particle dispersion models, Boundary Layer Meteorol., 90, 155-167, doi:10.1023/A:1001741110696

Stohl, A., M. Hittenberger, and G. Wotawa (1998), Validation of the Lagrangian particle dispersion model FLEXPART against large-scale tracer experiment data, Atmos. Environ., 32, 4245-4264, doi:10.1016/ S1352-2310(98)00184-8.

Stohl, A., C. Forster, A. Frank, P. Seibert, and G. Wotawa (2005), Technical note: The Lagrangian particle dispersion model FLEXPART version 6.2 Atmos. Chem. Phys., 5, 2461-2474, doi:10.5194/acp-5-2461-2005.

Textor, C., H.-F. Graf, M. Herzog, and J. M. Oberhuber (2003), Injection of gases into the stratosphere by explosive volcanic eruptions, J. Geophys. Res., 108(D19), 4606, doi:10.1029/2002JD002987.

Theys, N., M. van Roozendael, B. Dils, F. Hendrick, N. Hao, and M. De Maziere (2009), First satellite detection of volcanic bromine monoxide emission after the Kasatochi eruption, Geophys. Res. Lett., 36, L03809, doi:10.1029/2008GL036552.

Wang, X., et al. (2008), Volcanic dust characterization by EARLINET during Etna's eruptions in 2001-2002, Atmos. Environ., 42, 893-905, doi:10.1016/j.atmosenv.2007.10.020

Waythomas, C. F., S. G. Prejean, and D. J. Schneider (2008), Small volcano, big eruption, scientists rescued just in time, U.S. Dep. of the Inter., Washington, D. D. (Available at http://www.avo.alaska.edu/activity/ Kasatochi08/Kasatochi2008PLW.php.)

Wesely, M. L. (1989), Parameterization of surface resistances to gaseous dry deposition in regional-scale numerical models, Atmos. Environ. 23, 1293-1304, doi:10.1016/0004-6981(89)90153-4.

Wesely, M. L., and B. B. Hicks (1977), Some factors that affect the deposition rates of sulfur dioxide and similar gases on vegetation, J. Air Pollut. Control Assoc., 27, 1110-1116. 
Winker, D. M., W. H. Hunt, and M. J. McGill (2007), Initial performance assessment of CALIOP, Geophys. Res. Lett., 34, L19803, doi:10.1029/ 2007 GL030135.

Yang, K., N. A. Krotkov, A. J. Krueger, S. A. Carn, and P. K. Bhartia (2007), Retrieval of large volcanic SO2 columns from the Aura Ozone Monitoring Instrument: Comparison and limitations, J. Geophys. Res., 112, D24S43, doi:10.1029/2007JD008825.

Yang, K., X. Liu, N. A. Krotkov, A. J. Krueger, and S. A. Carn (2009a), Estimating the altitude of volcanic sulfur dioxide plumes from space borne hyper-spectral UV measurements, Geophys. Res. Lett., 36, L10803, doi:10.1029/2009GL038025.

Yang, K., N. A. Krotkov, A. J. Krueger, S. A. Carn, P. K. Bhartia, and P. F. Levelt (2009b), Improving retrieval of volcanic sulfur dioxide from back- scattered UV satellite observations, Geophys. Res. Lett., 36, L03102, doi:10.1029/2008GL036036.

L. Bitar and T. J. Duck, Department of Physics and Atmospheric Science, Dalhousie University Halifax, NS B3H 3J5, Canada.

S. Eckhardt, N. I. Kristiansen, A. J. Prata, K. Stebel, and A. Stohl, Norwegian Institute for Air Research, P.O. Box 100, N-2027 Kjeller, Norway. (nik@nilu.no)

A. Hoffmann and C. Ritter, Alfred Wegener Institute for Polar and Marine Research, Telegrafenberg A45, 14473 Potsdam, Germany.

A. Richter, Institute of Environmental Physics, University of Bremen, Otto-Hahn-Allee 1 D-28359 Bremen, Germany.

P. Seibert, Institute of Meteorology, University of Natural Resources and Applied Life Sciences (BOKU), Peter Jordan Str. 82A-1190 Wien, Vienna, Austria. 